\title{
Revisiting the Roles of Tobamovirus Replicase Complex Proteins in Viral Replication and Silencing Suppression
}

\author{
Nachelli Malpica-López, ${ }^{1}$ Rajendran Rajeswaran, ${ }^{1}$ Daria Beknazariants, ${ }^{1}$ Jonathan Seguin, ${ }^{1}$ \\ Victor Golyaev, ${ }^{1}$ Laurent Farinelli, ${ }^{2}$ and Mikhail M. Pooggin ${ }^{1,3,+}$ \\ ${ }^{1}$ University of Basel, Department of Environmental Sciences, Basel, Switzerland; ${ }^{2}$ Fasteris SA, Plan-les-Ouates, Switzerland; \\ and ${ }^{3}$ INRA, UMR BGPI, Montpellier, France
}

Accepted 17 September 2017.

\begin{abstract}
Tobamoviral replicase possesses an RNA-dependent RNA polymerase (RDR) domain and is translated from genomic (g)RNA via a stop codon readthrough mechanism at a one-to-ten ratio relative to a shorter protein lacking the RDR domain. The two proteins share methyltransferase and helicase domains and form a heterodimer implicated in gRNA replication. The shorter protein is also implicated in suppressing RNA silencing-based antiviral defenses. Using a stop codon mutant of Oilseed rape mosaic tobamovirus (ORMV), we demonstrate that the readthrough replicase (p182) is sufficient for gRNA replication and for subgenomic RNA transcription during systemic infection in Nicotiana benthamiana and Arabidopsis thaliana. However, the mutant virus displays milder symptoms and does not interfere with HEN1-mediated methylation of viral short interfering (si)RNAs or plant small (s)RNAs. The mutant virus tends to revert the stop codon, thereby restoring expression of the shorter protein (p125), even in the absence of plant Dicer-like activities that generate viral siRNAs. Plant RDR activities that generate endogenous siRNA precursors do not prevent replication or movement of the mutant virus, and double-stranded precursors of viral siRNAs representing the entire virus genome are likely synthesized by p182. Transgenic expression of p125 partially recapitulates the ORMV disease symptoms associated with overaccumulation of plant SRNAs. Taken together, the readthrough replicase p182 is sufficient for viral replication and transcription but not for silencing suppression. By contrast, the shorter p125 protein suppresses silencing, provokes severe disease symptoms, causes overaccumulation of unmethylated viral and plant sRNAs but it is not an essential component of the viral replicase complex.
\end{abstract}

Tobamoviruses are positive-sense RNA viruses replicating via a negative-sense RNA intermediate that serves as a template for the synthesis of their genomic RNA (gRNA) and the transcription of two subgenomic RNAs (sgRNAs) (Buck 1999; Ishikawa and Okada 2004). The viral coat protein (CP) and the movement protein (MP) are both translated from these sgRNAs

Nachelli Malpica-López and Rajendran Rajeswaran are joint first authors.

${ }^{\dagger}$ Corresponding author: Mikhail M. Pooggin;

E-mail: mikhail.pooggin@inra.fr.

*The $\boldsymbol{e}$-Xtra logo stands for "electronic extra" and indicates that two supplementary figures, one supplementary table, and three supplementary datasets are published online.

(c) 2018 The American Phytopathological Society
(sgRNA-CP and sgRNA-MP), while viral replication-associated proteins are synthesized directly from gRNA. The tobamoviral replicase polypeptide ( 178 to $183 \mathrm{kDa}$ ) is translated from an open reading frame (ORF) coding for a shorter 122- to $130-\mathrm{kDa}$ protein, via a stop codon readthrough mechanism that engages approximately $10 \%$ of arriving ribosomes and adds a C-terminal RNAdependent RNA polymerase (designated here as viral RDR) domain. The shorter protein, which is present at an approximately 10-fold molar excess over the readthrough replicase (Watanabe et al. 1999), shares with it methyl transferase/guanylyl transferase and helicase domains that play a role in replication and capping of gRNA and sgRNAs. Both proteins associate into membranebound heterodimers that participate in viral RNA replication (Hagiwara et al. 2003; Komoda et al. 2007; Nishikiori et al. 2012; Osman and Buck 1996; Watanabe et al. 1999). The excessive shorter protein also forms soluble oligomers (Watanabe et al. 1999). Notably, non-membrane bound (but not membrane-bound) fraction of these proteins has been implicated in the suppression of RNA silencing-based plant antiviral defenses (Hagiwara-Komoda et al. 2008).

RNA silencing is a sequence-specific mechanism that regulates gene expression and defends against invasive nucleic acids such as transposons, transgenes, and viruses in most eukaryotes (Ghildiyal and Zamore 2009). In plants, RNA silencing is directed by 21 - to 24-nucleotide (nt) small RNAs (sRNA), classified into short interfering RNAs (siRNA) and microRNAs (miRNA), which are produced as duplexes with 2-nt 3' overhangs from longer double-stranded RNA (dsRNA) precursors or hairpin-like secondary structures, respectively, by Dicer-like (DCL) enzymes. Both strands of each sRNA duplex are methylated at the $2^{\prime}$ hydroxyl of their $3^{\prime}$ terminal nucleotide by methyltransferase HEN1 (Yang et al. 2006; Yu et al. 2005) and then sorted, based mostly on size and the identity of their 5' terminal nucleotide, by Argonaute (AGO) family proteins to form RNA-induced silencing complexes (RISCs) (Havecker et al. 2010; Mi et al. 2008). Mature RISCs contain a singlestranded sRNA that guides AGO toward complementary RNA targets to silence gene expression post-transcriptionally through AGO-sRNA-directed cleavage or translational repression of the target mRNA or transcriptionally through AGO-sRNA-directed DNA methylation and chromatin modification (Havecker et al. 2010). Gene silencing directed by both miRNAs and siRNAs can, in some cases, be reinforced by plant RDR enzymes that generate dsRNA precursors for secondary siRNAs (Howell et al. 2007; Rajeswaran and Pooggin 2012; Rajeswaran et al. 2012; Wassenegger and Krczal 2006).

In plants, RNA silencing pathways are extremely diverse, involving multiple combinations of RDRs, AGOs, and DCLs of differing specificities. For instance, the genome of Arabidopsis 
thaliana encodes six RDRs, ten AGOs, and four DCLs. Although the latter can all process RDR-independent dsRNA (Blevins et al. 2011; Fusaro et al. 2006), they do exhibit differences regarding substrate preference (DCL1 processes preferentially Pol II-transcribed MIR gene transcripts, while DCL2, DCL3, and DCL4 prefer RDR6- or RDR2-dependent dsRNA precursors) and product size (21- to 22-nt miRNA duplexes for DCL1, 22-nt siRNA for DCL2, 24-nt siRNA for DCL3, and 21-nt siRNA for DCL4) (Blevins et al. 2015; Bouché et al. 2006; Howell et al. 2007; Mlotshwa et al. 2008; Parent et al. 2015; Rajeswaran et al. 2012; Zhai et al. 2015). It is, therefore, unsurprising that, although all four A. thaliana DCLs are involved in the generation of viral siRNAs (Blevins et al. 2006; Bouché et al. 2006; Diaz-Pendon et al. 2007; Fusaro et al. 2006), their impact on antiviral defense depends on the identity of the infecting virus. RNA viruses with cytoplasmic replication and transcription (such as tobamoviruses) are targeted mainly by DCL4 and, in some cases, DCL2 (Andika et al. 2015; Blevins et al. 2006; Bouché et al. 2006; Fusaro et al. 2006; Xie et al. 2004), while DNA viruses with nuclear transcription are targeted by DCL3 and DCL1 in addition to DCL4 and DCL2 (Akbergenov et al. 2006; Aregger et al. 2012; Blevins et al. 2006, 2011).

A similar picture has emerged regarding other components of the RNA silencing machinery. RDR1, RDR2, and RDR6 have been implicated in defense against RNA viruses, albeit the relative contribution (if any) of these RDRs to the biogenesis of viral secondary siRNAs appears to depend on viral genus, strain, or mutant variant (Donaire et al. 2008; Garcia-Ruiz et al. 2010; Lee et al. 2016; Schwach et al. 2005; Qi et al. 2009; Qu et al. 2005; Vaistij and Jones 2009; Wang et al. 2010, 2011; Yang et al. 2004; Yu et al. 2003), while neither RDR1, RDR2, nor RDR6 appear to play a significant role in the biogenesis of DNA virus-derived siRNAs in A. thaliana (Aregger et al. 2012; Blevins et al. 2011). Likewise, among multiple AGOs implicated in plant antiviral defense mechanisms (Carbonell and Carrington 2015), AGO2 seems to play a major role (Harvey et al. 2011; Ghoshal and Sanfaçon 2014; Ma et al. 2015; Odokonyero et al. 2015; Scholthof et al. 2011), owing to its ability to bind viral siRNAs (Harvey et al. 2011; Wang et al. 2011) and form antiviral RISCs with cleavage or slicer activity (Garcia-Ruiz et al. 2015), while AGO1 may play both direct and indirect roles via its association with viral siRNAs (Garcia-Ruiz et al. 2015; Wang et al. 2011) or plant miRNAs, respectively; in the latter case, AGO1-miR403-directed repression of AGO2 mRNA controls the accumulation of $\mathrm{AGO} 2$ protein and, hence, its antiviral activity (Harvey et al. 2011).

To counteract these defense mechanisms, most plant viruses have evolved anti-silencing strategies targeting different steps of the biogenesis or action of viral siRNAs as well as plant miRNAs (Csorba et al. 2015). One such strategy involves the induction of miR168 (Várallyay et al. 2010, 2013), which participates in AGO1 mRNA repression via a feedback loop involving AGO1 itself (Vaucheret et al. 2006), while another, very common strategy employed by RNA viruses involves the binding of sRNA duplexes by a viral suppressor protein, preventing their methylation by HEN1 or RISC assembly, as shown in A. thaliana and N. benthamiana (Lakatos et al. 2006; Lózsa et al. 2008; Mérai et al. 2006). The shorter tobamoviral replication protein appears to be one such RNA silencing suppressor, as demonstrated by transient assays in $N$. benthamiana with a $130-\mathrm{kDa}$ protein (p130) of Tomato mosaic virus (ToMV) (Kubota et al. 2003), p126 of Tobacco mosaic virus (TMV) (Ding et al. 2004; Vogler et al. 2007) and TMV-Cg (Kurihara et al. 2007), and p122 of crucifer-infecting TMV (Csorba et al. 2007). p122 and p126 from two different crucifer-infecting tobamoviruses were shown to bind sRNA duplexes (Csorba et al. 2007; Kurihara et al. 2007), which might inhibit their methylation and subsequent RISC assembly (Csorba et al. 2007). Interestingly, sRNA duplex-binding activity was exhibited only by a non-membrane bound form of the ToMV replicase complex (Hagiwara-Komoda et al. 2008). In any case, since anti-silencing activities of the shorter replication protein have so far been demonstrated in transient assays or in vitro, it remains unclear whether, during tobamovirus infection, this protein alone is sufficient for suppressing HEN1-mediated methylation and antiviral silencing or if it needs to form a heterodimer with the longer readthrough replicase. Likewise, it remains unknown whether the longer protein can also suppress silencing on its own.

Oilseed rape mosaic virus (ORMV) (Aguilar et al. 1996), also known as Youcai mosaic virus, Ribgrass mosaic virus, or Chinese rape mosaic virus, is a tobamovirus that can establish systemic infection and cause severe disease in both A. thaliana and N. benthamiana (Mansilla et al. 2009; Seguin et al. 2014). In A. thaliana, ORMV interferes with HEN1-mediated methylation of viral siRNAs (Akbergenov et al. 2006; Blevins et al. 2006), leading to the accumulation of nonmethylated viral siRNAs and plant sRNAs, including miRNAs and transacting siRNAs (tasiRNAs) as well as their passenger strands (miRNA* and tasiRNA*), which are normally degraded (Akbergenov et al. 2006; Blevins et al. 2006; Hu et al. 2011; Vogler et al. 2007). However, the precise roles played by the two ORMV replicase components (the shorter protein $\mathrm{p} 125$ and the readthough replicase p182) in this phenomenon have not been determined. Also, although it has been shown that ORMV siRNA biogenesis in A. thaliana (Columbia-0 [Col-0]) plants depends largely on DCL4 and is independent of RDR2 and RDR6 (Blevins et al. 2006), further detail on the mechanisms of antiviral silencing and its suppression during ORMV infections is lacking. Therefore, we constructed a p125-deficient mutant of ORMV and used it to dissect the function of both the 125 and p182 proteins in A. thaliana and its siRNA biogenesis-deficient mutant lines as well as in $N$. benthamiana, employing blot hybridization and deep sequencing of sRNAs to characterize their impact on the RNA silencing machinery.

\section{RESULTS}

To better understand the induction and suppression of antiviral silencing during ORMV infection, we performed an in-depth molecular characterization of wild-type A. thaliana (Col-0) and of the siRNA biogenesis-deficient triple mutant lines $d c l 234$ ( $d c l 2-5$ $d c l 3-1$ dcl4-2) (Blevins et al. 2006) and rdr126 (rdr1-1 rdr2-1 rdr6-15) (Blevins et al. 2011) at 5, 14, and 22 days postinoculation (dpi) with wild-type ORMV or a p125 stop codon mutant (UAGto-UAC) derivative expressing p182 but not p125 (Fig. 1E). The plants were inoculated either with ORMV sap or with in vitro transcripts of viral gRNA from wild-type and mutant virus clones, designated W41 and M41, respectively (Fig. 1E). Viral RNAs and proteins were analyzed by Northern (Fig. 1A and C) and Western (Fig. 1F) blotting, respectively, while viral and endogenous sRNAs were analyzed by blot hybridization (Fig. 1B and D) and then by Illumina sequencing.

\section{Double-stranded intermediates of viral replication appear to be major substrates for DCLs.}

At all three timepoints, viral gRNA and sgRNAs accumulated to higher levels in $d c l 234$ than in Col-0 plants (Fig. 1A and $\mathrm{C}$ ), coinciding with much lower levels of viral siRNAs (Fig. $1 \mathrm{~B}$ and D) (discussed below). This finding is consistent with previous results implicating DCL4 along with DCL2 and DCL3 in ORMV siRNA biogenesis and antiviral defense (Blevins et al. 2006). In the rdr126 host, viral gRNA and sgRNAs also accumulated to higher levels than in Col-0 at 14 and $22 \mathrm{dpi}$ (Fig. 1A) and to comparable levels at 5 dpi (Fig. 1C). However, 
despite the absence of three RDRs known to generate plant siRNA precursors, viral siRNA production was not abolished in this background (Fig. 1B and D) (discussed below). A. thaliana has three additional $R D R$ genes of unknown function $(R D R 3 a$, $R D R 3 b$, and $R D R 3 c$ ) (Wassenegger and Krczal 2006) whose potential contribution to viral siRNA biogenesis in $r d r 126$ plants cannot be formally ruled out. However, it would be plausible for DCLs to directly generate ORMV siRNAs from intermediate dsRNA forms arising during gRNA replication and sgRNA transcription.

A genome-sized long antisense RNA, designated gRNA(-), likely functioning as a template for gRNA replication and sgRNA transcription as well as a relatively more abundant short antisense RNA, comparable in size to sgRNA-CP, and hence, designated $\mathrm{CP}(-)$, were detected by means of strand-specific ORMV probes (Fig. 1A and C). Previously, dsRNA species with sizes corresponding to viral gRNA and sgRNAs were isolated from TMV-infected plants (Palukaitis et al. 1983). At 5 dpi, gRNA(-) was detectable only in $d c l 234$ (Fig. 1C), which might suggest that DCLs are targeting dsRNA viral replication intermediates since the earliest stages of viral infection. However, at the later timepoints (14 and $22 \mathrm{dpi}), \operatorname{gRNA}(-)$ accumulation in $d c l 234$ was not greater than in Col-0 (Fig. 1A).

\section{SRNA sequencing uncovers mechanisms of viral siRNA biogenesis.}

Illumina sequencing of the 19- to 30-nt fraction from total RNA samples of mock-inoculated and ORMV sap-infected A. thaliana Col-0, rdr126, and $d c l 234$ plants at 14 and 22 dpi (used for Northern analysis shown in Figure 1A) yielded 12 libraries, each containing 3.1 to 7.8 million reads. The majority of these reads fell into a size range of 20 to $25 \mathrm{nt}$, known to be populated by endogenous plant miRNAs and siRNAs as well as viral siRNAs. This size range was selected for further bioinformatics analysis (Supplementary Dataset S1, mapping and counting sRNAs sorted by size, polarity and $5^{\prime}$-nt identity as described below for $A$. thaliana and $N$. benthamiana).

Zero-mismatch mapping of the sRNA reads to the $120-\mathrm{Mb}$ A. thaliana TAIR10 reference genome and the 6.3-Kb ORMV genome revealed that viral sRNAs represented a large fraction (27\% at $14 \mathrm{dpi}$ and $23 \%$ at $22 \mathrm{dpi}$ ) (Fig. 2A) of the 20- to $25-\mathrm{nt}$ sRNA population in ORMV-infected Col-0 plants. This proportion was even larger in ORMV-infected $r d r 126$ plants $(35 \%$ at $14 \mathrm{dpi}$ and $31 \%$ at $22 \mathrm{dpi}$ ) (Fig. 2A). However, since endogenous siRNA biogenesis is diminished in $r d r 126$, thereby increasing the proportion of 21-nt reads (mostly representing miRNAs) within the 20- to 25-nt Arabidopsis reads (Fig. 2B), we decided to normalize viral reads to the number of 21-nt endogenous Arabidopsis reads. The resulting figures were roughly equivalent between $r d r 126$ and Col-0 at 14 dpi (894,214 versus $908,107)$ and only slightly higher in $r d r 126$ at 22 dpi $(898,249$ versus 792,706). Moreover, the size profiles of viral reads did not differ significantly between $r d r 126$ and Col-0; in both cases, 21 -nt reads predominated (67 to $70 \%$ of 20 - to 25 -nt viral reads), followed by 20 -nt (13 to $14 \%$ ) and 22 -nt (7 to $9 \%$ ) reads (Fig. 2B). Likewise, no substantial differences in the $5^{\prime}$ nucleotide profile or viral genome distribution (Fig. 3) (discussed below) of viral reads were observed between Col-0 and $r d r 126$ at any timepoint. Taken together, our findings indicate that RDR1, RDR2, and RDR6 are not essential for viral siRNA biogenesis.

The size profile of endogenous sRNAs changed significantly upon ORMV infection. At both 14 and 22 dpi, 21-nt reads became the most abundant, surpassing the 24-nt reads that dominated in mock-inoculated Col-0 plants (Fig. 2B). A similar shift in sRNA size profiles was previously reported for ORMVinfected $A$. thaliana at $7 \mathrm{dpi}$, when it was found to correlate with overaccumulation of many miRNAs as well as miRNA* and siRNA* passenger strands (Hu et al. 2011), and at 22 dpi in an earlier study (Blevins et al. 2006). We validated these findings for selected miRNAs and tasiRNAs by blot hybridization (Fig. 1B and D). Indeed, the accumulation of miR168, miR472, miR472*, and siR255* was much higher in ORMVinfected than mock-inoculated plants at both 14 and $22 \mathrm{dpi}$, while extra bands of longer and shorter size appeared for miR403 and miR173 in ORMV-infected plants (Fig. 1B). Similar (although less pronounced) effects were observed for miR168, miR472*, and siR255* at $5 \mathrm{dpi}$ (Fig. 1D). Notably, the levels of both miRNA and miRNA* were comparable between Col-0, dcl234, and $r d r 126$ plants (Fig. 1B and D). The latter finding indicates that endogenous RDRs are not involved in the upregulation of miRNA and miRNA* species triggered by ORMV infection and validates the normalization procedure followed here for comparing viral siRNA levels between siRNA-deficient mutant lines and Col- 0 .

The number of viral sRNA reads was substantially lower in ORMV-infected $d c l 234$ plants compared with Col-0 or $r d r 126$ individuals. In this genetic background, viral reads represented only 11 and $12 \%$ of 20 - to 25 -nt reads at 14 and 22 dpi, respectively, which, when normalized per million Arabidopsis 21-nt reads, represents frequencies four- and threefold lower than those of the corresponding timepoints in $r d r 126$ or Col0 plants (Fig. 2B). The size profile of viral reads in $d c l 234$ plants also was different at the two timepoints, with 21-nt reads constituting only $23 \%$ of 20 - to 25 -nt viral reads, i.e., three times lower than in $r d r 126$ or Col-0 plants (Fig. 2B). This is consistent with previous results implicating DCL4 in the biogenesis of 21-nt viral siRNAs in ORMV-infected Arabidopsis (Blevins et al. 2006). However, our finding that viral siRNA production was not abolished in $d c l 234$ plants indicates that, in this species, the viral siRNA precursors can also be processed, although in a less efficient and precise manner, by DCL1 or one or more other RNase III-like endonucleases that produce an sRNA population of broader and more evenly distributed size classes, exhibiting comparable numbers of 20-, 22-, 23-, 24-, and 25-nt reads in addition to the slightly more abundant 21-nt reads (Fig. 2B). Note that the Illumina protocol used in our study only sequences RNA molecules bearing $5^{\prime}$ monophosphate and $3^{\prime}$ hydroxyl groups, which are typical of DCL and RNase III cleavage products.

An inspection of single-nucleotide resolution maps of ORMVderived 20- to 25-nt reads revealed that viral siRNAs span the entire virus genome in both sense and antisense orientations, without gaps in any strand (Fig. 3; Supplementary Dataset S2). No strong strand bias of total 20- to 25-nt reads was observed in Col-0 or rdr126 plants (Fig. 3). Furthermore, no substantial difference in the sRNA maps for individual size classes was observed between the wild-type Col-0 and the $r d r 126$ mutant lacking RDR1, RDR2, and RDR6 at both 14 and 22 dpi (Fig. 3), supporting our hypothesis that viral siRNAs are processed from RDR-independent dsRNA precursors. In contrast, a strong bias toward gRNA(+) polarity was observed in $d c l 234$ plants, in which sense reads exceeded antisense reads approximately ninefold at both 14 (324,360 versus 34,565$)$ and 22 dpi $(420,344$ versus 46,262). Interestingly, most antisense reads belonged to the 21-nt size class (Fig. 3) or the less-abundant 20-nt size class, while sense reads were more evenly distributed across other size classes, pointing at possible involvement of DCL1 in production of viral sRNAs in the absence of other DCLs. Interestingly, in Col-0 and rdr126 plants (possessing all four DCLs) a strong sense strand bias was only detected among the low abundance 23-, 24-, and 25-nt reads (Fig. 3).

\section{p125 is not essential for viral replication or movement but has a strong impact} on silencing suppression and disease severity.

Viral silencing suppressors can interfere with the antiviral activities of specific components of the RNA silencing machinery, 
which explains why the susceptibility of wild-type plants to certain viruses is often undistinguishable from that of mutant plants lacking the targeted components. For instance, it was only by using suppressor-deficient mutants of Cucumber mosaic virus (CMV) and Turnip mosaic virus (TuMV) that the involvement of RDR6 and RDR1 in the biogenesis of secondary viral siRNAs and antiviral defense in Arabidopsis was demonstrated (GarciaRuiz et al. 2010; Wang et al. 2010, 2011). Therefore, in an effort to dissect the involvement of the short and long (p125 and p182, respectively) components of the ORMV replicase complex in silencing suppression, we generated a mutant virus that can synthesize $\mathrm{p} 182$ but not $\mathrm{p} 125$ by changing the stop codon of the latter from TAG to TAC (which codes for tyrosine, the amino acid normally incorporated at this position, via translational readthrough in other tobamoviruses) (Fig. 1E). The mutation was introduced into ORMV infectious clone W41, where the 6,303-nt consensus viral sequence (Seguin et al. 2014) is placed under control of a T7 RNA polymerase promoter, as
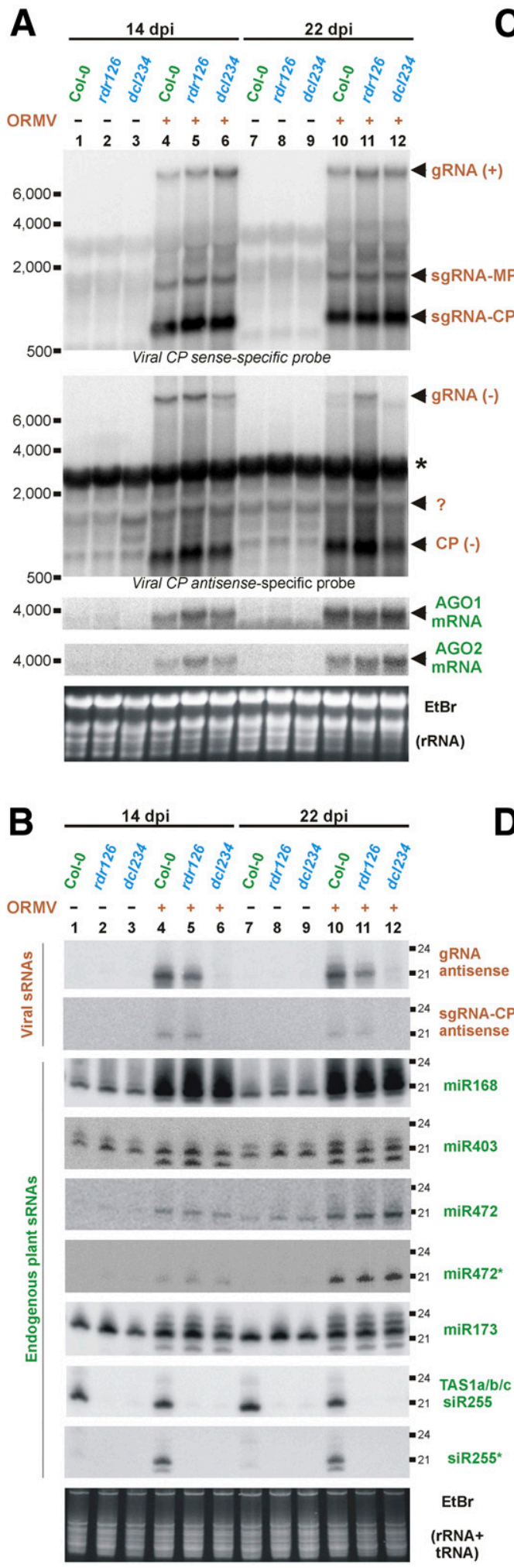

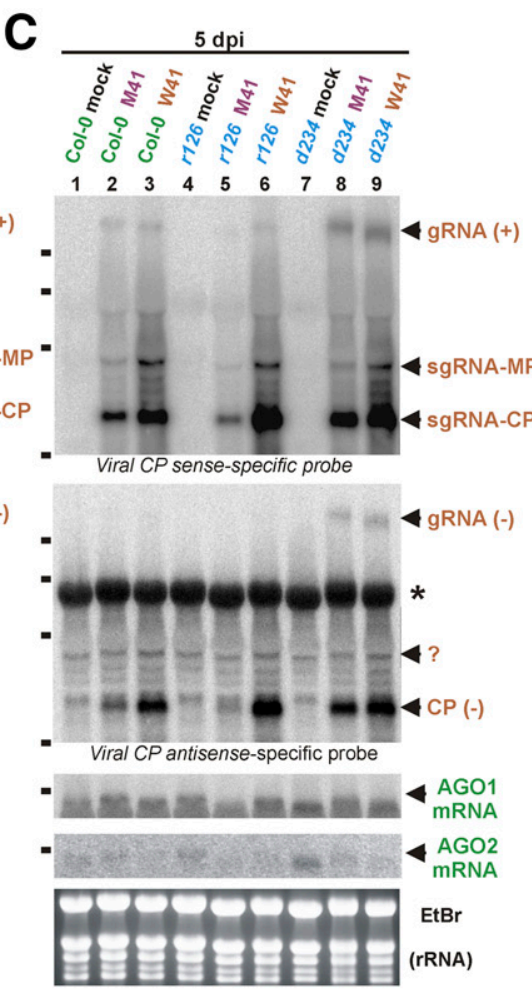

D

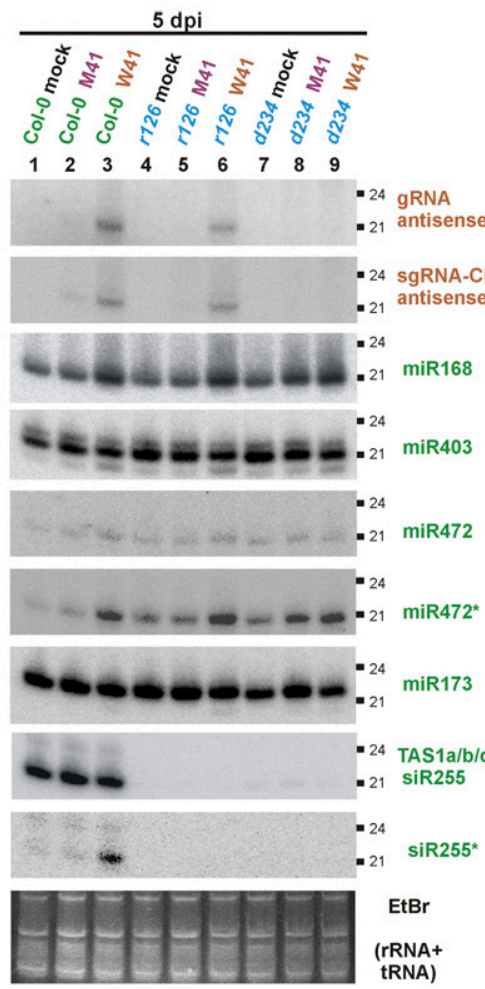

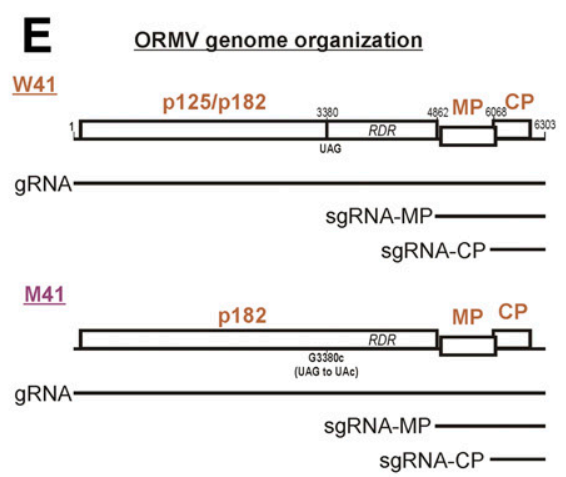

$\mathbf{F}$
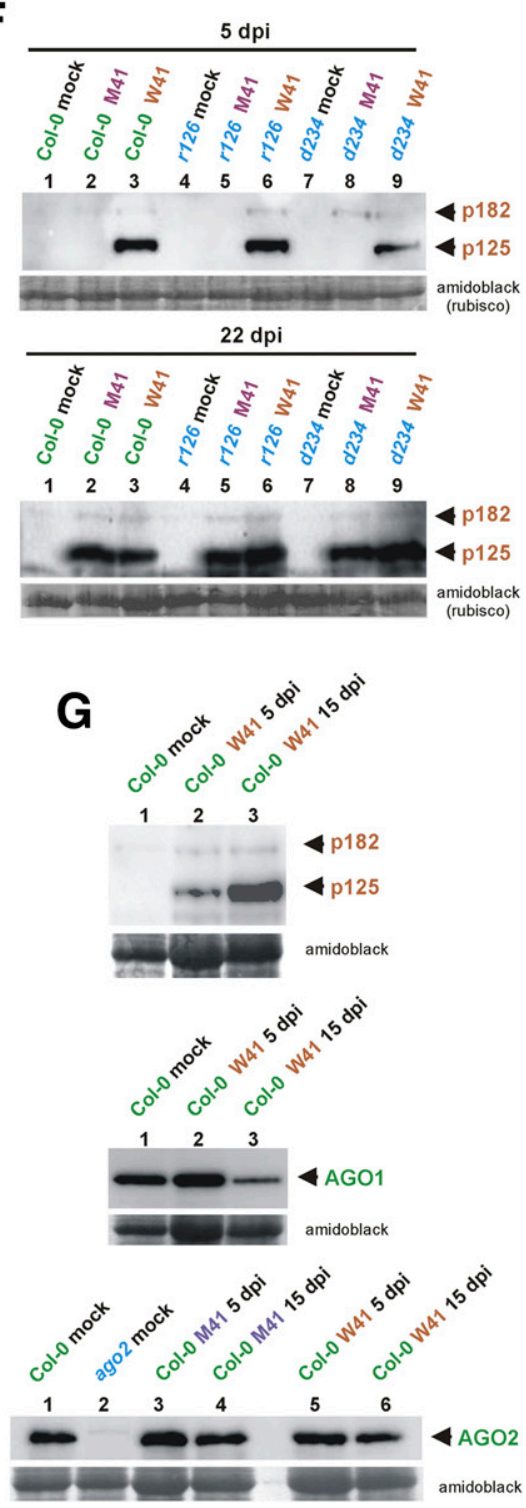
well as into its W4 derivative, which carries a nonconsensus T-to-G substitution at position 5612, obtaining the mutant clones M41 and M4. The parental clones W41 and W4 produce, upon delivery into A. thaliana Col-0 or $N$. benthamiana plants via inoculation of in vitro transcripts, a disease whose symptoms and severity are similar to those appearing after inoculation with wildtype ORMV virions (Hu et al. 2011; Seguin et al. 2014; data not shown).

Following inoculation into A. thaliana Col-0, rdr126, and dcl234 plants, clones M41 and M4 exhibited lower virulence than their parental constructs, producing less severe symptoms by $22 \mathrm{dpi}$, which correlated with a reduced accumulation of viral gRNA(+). Reverse transcription-polymerase chain reaction (PCR) and sequencing analysis revealed that, in all the M41- and M4-infected Col-0, rdr126, and $d c l 234$ plants of that timepoint, a p125 stop codon had reappeared in most viral gRNA molecules via an UAC-to-UAA reversion and only a small fraction of viral RNA still carried the mutant UAC codon at this position. These results confirm earlier findings in TMV, where a similar UAG to UAU mutation at the stop codon was reverted in vivo to UAA (Ishikawa et al. 1986). The stop codon reversions restored $\mathrm{p} 125$ protein expression, which accumulated by $22 \mathrm{dpi}$ at the levels comparable to those from the wild-type virus (W41) in all the plants (Fig. 1F, lower blot).

It is notable that even the impairment in siRNA biogenesis in rdr126 and $d c l 234$ plants (e.g., the tasiRNA siR255 shown in Figure $1 \mathrm{~B}$ and $\mathrm{D}$ ) did not compensate for the strong selective disadvantage suffered by p125-deficient viruses, as evidenced by their displacement by stop codon revertants along the course of the infection. However, the p125-deficient mutants could replicate and move systemically during the early stages of infection, because no p125 expression was detected in systemic leaves of M41-infected Col-0, rdr126, or $d c l 234$ plants at $5 \mathrm{dpi}$ (Fig. 1F, upper blot, lanes 2, 5, and 8). Consistently, no reversion of the stop codon was detected by deep sequencing and bioinformatic analysis of M41 gRNA-derived small RNAs at 5 dpi (discussed below). The gRNA and sgRNAs of M41 accumulated in all these plants, albeit at lower levels than in W41infected plants (Fig. 1C, compare lanes 2, 5, and 8 with lanes 3,6 , and 9). Notably, mutant virus RNAs did not accumulate to higher levels in $r d r 126$ than in Col-0 (Fig. 1C), indicating that one or both the replication and systemic movement of the p125-deficient virus are not promoted in the absence of RDR1, RDR2, and RDR6. On the other hand, they accumulated to higher levels in $d c l 234$ than in Col-0 (Fig. 1C), indicating that the three DCLs substantially inhibit one or both the replication and systemic movement of the p125-deficient virus. Viral gRNA accumulated to comparable levels in M41- and W41-infected dcl234 plants (Fig. 1C, lane 8 versus 9), as was the p182 protein (Fig. 1F, upper blot, lane 8 versus 9), which, by contrast, was barely detectable in M41-infected Col-0 and rdr126 plants at 5 dpi (Fig. 1F, upper blot, lanes 2 and 5). Hence, p125-deficient viruses replicated gRNA and translated p182 more efficiently when DCL-mediated viral siRNA biogenesis was impaired.

To further examine whether p125 might affect viral siRNA biogenesis by inhibiting the activity of plant RDR1, RDR2, or RDR6 and whether p182 alone has any influence on the plant sRNA-generating machinery, we deep-sequenced sRNAs from Col-0 and $r d r 126$ plants systemically infected with M41 or W41 at 5 dpi. Bioinformatic analysis of viral sRNA reads revealed no stop codon reversion, confirming that the mutant virus population had not yet been overtaken by p125 stop codon revertants at this timepoint. W41-derived sRNAs comprised a large fraction of the 20- to 25-nt reads in both Col-0 and $r d r 126$, even larger than that of endogenous Arabidopsis sRNAs reads (Fig. 4A). When normalized to 21-nt endogenous Arabidopsis reads, the accumulation of viral siRNAs was similar in Col-0 $(2,800,511)$ and $r d r 126$ plants $(2,852,744)$. Moreover, an analysis of viral sRNA size classes (Fig. 4B), single nucleotide resolution maps (Fig. 5) and $5^{\prime}$ nucleotide profiles did not find any significant difference between the ORMV-derived siRNAs of Col-0 and rdr126 plants, indicating that RDR1, RDR2, and RDR6 do not play a significant role in the generation of siRNAs from wild-type virus at $5 \mathrm{dpi}$ and, thus, extending the scope of our above-described findings for 14 and 22 dpi. Mutant (M41) virus-derived sRNAs accumulated to lower levels than W41derived sRNAs in both Col-0 and rdr126 (Figs. 4A and 1D), which correlated with the lower amount of viral long RNAs in the corresponding samples (Fig. 1C). Although the normalized numbers of viral 20- to 25-nt reads for M41 in rdr126 $(181,155)$ were 2.5-fold lower than in Col-0 (442,742), which might be interpreted as a sign of RDR involvement in the production of secondary viral siRNAs in wild-type plants, as argued in earlier studies (Garcia-Ruiz et al. 2010; Wang et al. 2010, 2011), it should be pointed out that the amount of M41 long RNAs from which siRNAs are derived is also approximately threefold lower in $r d r 126$ than in Col-0 (Fig. 1C, lanes 5 versus 2). Furthermore, there are no significant differences between the size profiles (Fig. 4B), single-nucleotide resolution maps (Fig. 5) and $5^{\prime}$ terminal nucleotide identities of mutant virus-derived sRNAs between Col-0 and rdr126. Taken together, our data indicate that, at the early stages of infection, host RDR activity does not appear to restrict replication of the p125-deficient mutant virus. Also, viral p125 does not appear to inhibit the activities of any of the three host RDRs during wild-type virus

\section{$\leftarrow$}

Fig. 1. Long RNA analysis (1\% agarose denaturing gel) of Oilseed rape mosaic tobamovirus (ORMV) positive-sense RNAs (gRNA, sgRNA-MP, sgRNA-CP) and negative-sense RNAs [gRNA(-) and $\mathrm{CP}(-)$ ] and of Arabidopsis thaliana AGO1 and AGO2 mRNAs in mock-inoculated (-) and virus-infected (+) Col-0, rdr126, and dcl234 plants A, at 14 and 22 days postinoculation (dpi) with ORMV sap, and C, at 5 dpi with W41 and M41 in vitro transcripts. In each experiment, total RNA was extracted from systemic leaf pools of three plants for each condition. The cropped scans represent the blots successively hybridized with DNA oligonucleotide probes specific for the viral coat protein (CP) sense and antisense strands and the AGO1 and AGO2 coding strands. The positions of RNA size markers are indicated on each scan. An abundant plant ribosomal (r)RNA species cross-hybridized with the viral CP antisense-specific oligonucleotide probe is indicated by an asterisk. The question mark (?) indicates a presumptive viral movement protein-lacking (MP-) RNA species, the reliable detection of which is prevented by probe cross-hybridization to a comigrating plant RNA species. Ethidium bromide (EtBr)-stained rRNA is shown as a loading control. B and D, High-resolution small (s)RNA analysis (15\% polyacrylamide gel electrophoresis) of the same total RNA samples as in A and C. The blots were successively hybridized with DNA oligonucleotide probes specific for viral antisense short interfering (si)RNAs derived from ORMV p125 and CP as well as for plant micro (mi)RNA (miR168, miR403, miR472, miR173), miRNA* (miR472*), si)RNA (siR255), and siRNA* (siR255*) species. sRNA sizes are indicated. The EtBr-stained gel is shown as loading control. E, The genome organization of ORMV wild-type (W41) and mutant (M41) viruses. The open reading frames are boxed and the encoded proteins (p125, p182, MP, and CP) are indicated above them. Positions of the p125 stop codon (UAG) in W41 and its mutation (UAG to UAc) in M41 are indicated. Viral genomic (gRNA) and subgenomic (sgRNA-CP and sgRNA-MP) RNAs are depicted by lines. F and G, Western blots of ORMV p125 and p182 and A. thaliana AGO1 and AGO2 in Col-0, rdr126, dcl234, and ago2 plants infected with M41 or W41 at 5, 15, and 22 dpi. In each case, a systemic leaf pool of three plants was used for protein extraction. The membranes were incubated with antip125, anti-AGO1, or anti-AGO2 antibodies and were stained with Amido Black afterward to use the Rubisco bands as loading controls. The positions of p125 and p182 are indicated with arrows. Note that, in this experiment, the ORMV p125/p182-specific antibody cross-hybridized to a plant protein migrating just above p182 (Col-0 mock lane). Note that the experiments were replicated at least two times with similar results. 
infections, as no differences are apparent between the studied RDR-dependent endogenous siRNAs in wild-type or mutant virus infections (Fig. 1D).

To verify and extend the above findings to another host plant species, we tested if p125 deficiency also affects ORMV infection in the solanaceous plant $N$. benthamiana. Inoculation of $N$. benthamiana seedlings with wild-type ORMV virions or with in vitro-transcribed RNA from W41 or W4 resulted in severe disease symptoms, including stem necrosis and wilting at $5 \mathrm{dpi}$, followed by rapid plant death within a few days

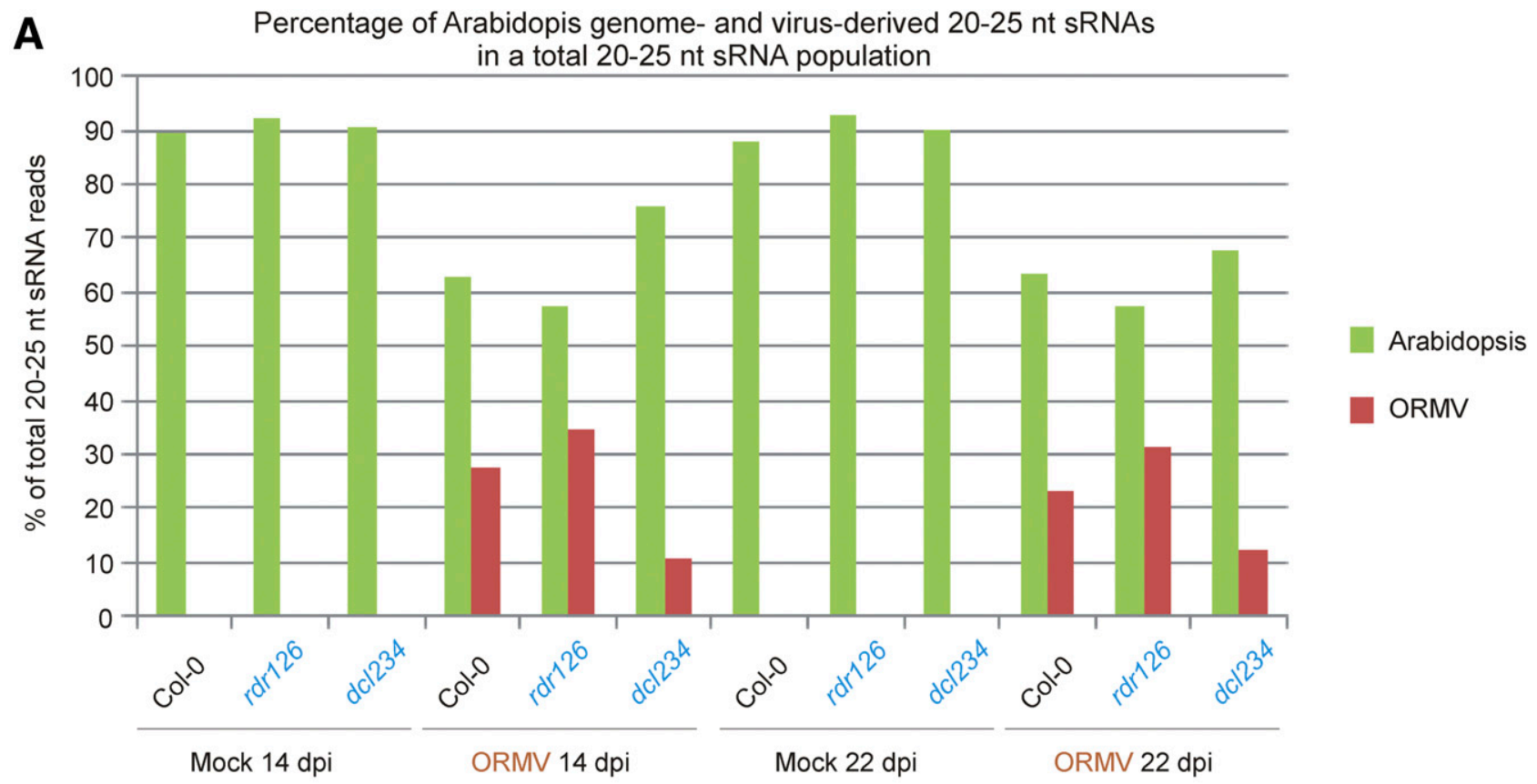

B Percentage of 20-nt, 21-nt, 22-nt, 23-nt, 24-nt and 25-nt sRNAs in total 20-25 nt sRNA populations of the plant endogenous and viral SRNAs
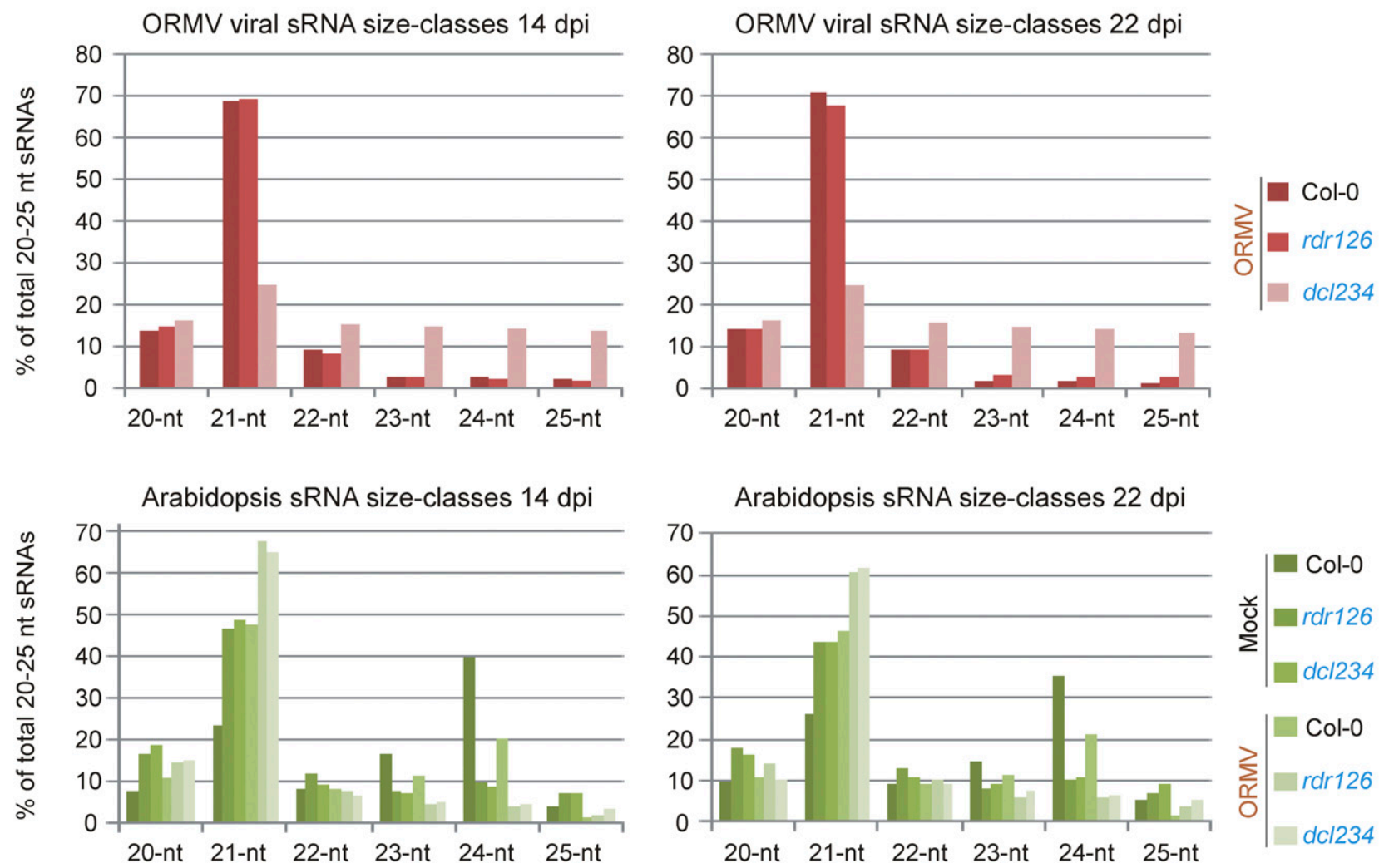

Fig. 2. Illumina sequencing counts of endogenous and viral small (s)RNAs in mock-inoculated and Oilseed rape mosaic tobamovirus (ORMV)-infected Arabidopsis thaliana (Col-0, rdr126, or dcl234) at 14 and 22 days postinoculation (dpi). A, Percentages of virus- and plant-derived sRNAs that mapped to ORMV or Arabidopsis genome reference sequences with zero mismatches in the pool of total 20- to 25-nt reads. B, Percentages of each size class for 20- to 25-nt virus- or Arabidopsis-derived sRNA reads that mapped to the corresponding reference sequence with zero mismatches. Note that aliquots of the same total RNA samples (extracted from systemic leaf pools of three plants per each condition) was used for both Illumina sequencing and blot hybridization analyses. 
(Seguin et al. 2014). In contrast, inoculation with in vitrotranscribed RNA from p125-deficient viruses (M41 or M4) did not result in plant death, although disease symptoms were observed in upper (systemic) leaves of M41- and M4-infected

ORMV genomic RNA
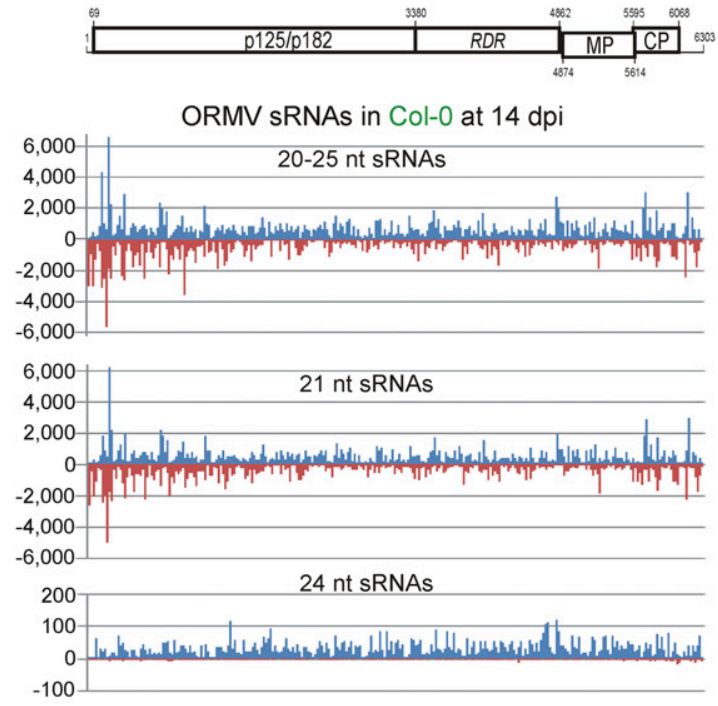

ORMV sRNAs in rdr126 at $14 \mathrm{dpi}$

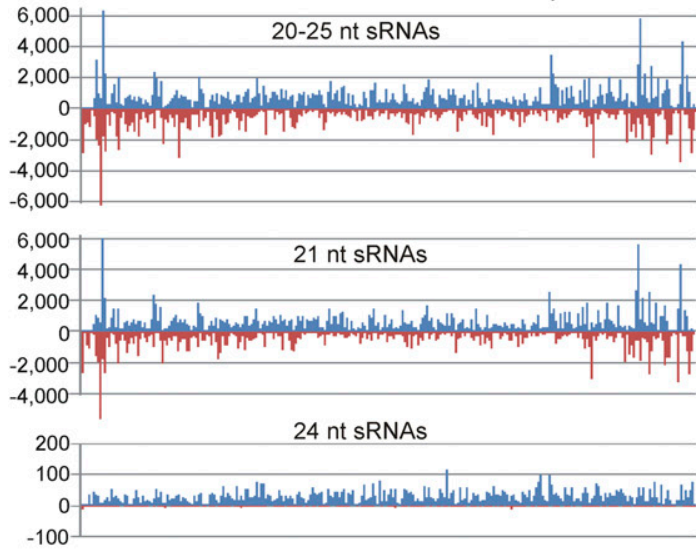

ORMV sRNAs in $d c / 234$ at $14 \mathrm{dpi}$ 20-25 nt sRNAs
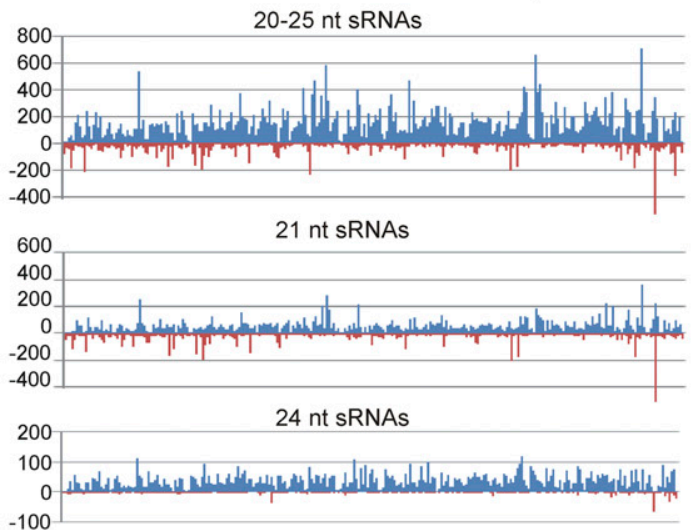

plants at 26 dpi. The accumulation of viral gRNA and sgRNAs at 5 dpi for M41 and M4 was about twofold lower than for W41 and $\mathrm{W} 4$, and the accumulation of the mutant virus RNAs were significantly lower at $26 \mathrm{dpi}$ than at $5 \mathrm{dpi}$, suggesting that plant

\section{ORMV genomic RNA}
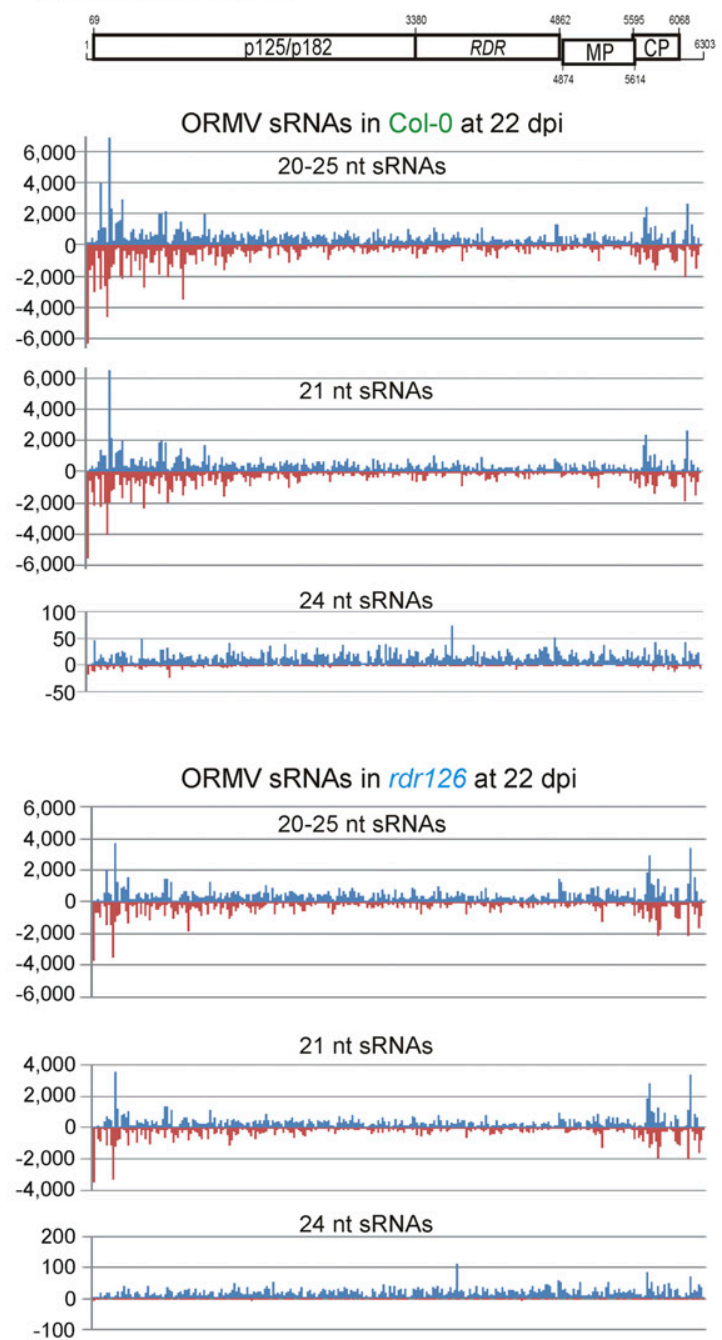

ORMV sRNAs in dc/234 at $22 \mathrm{dpi}$ 20-25 nt sRNAs
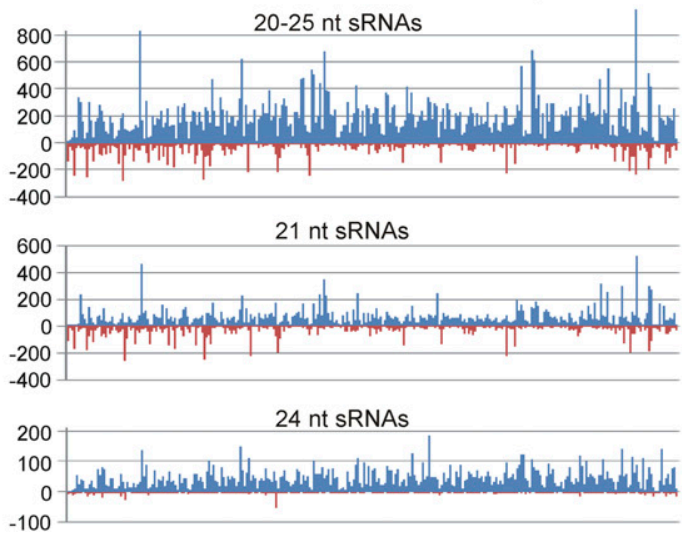

Fig. 3. Single-nucleotide resolution maps of 20- to 25-nt viral short interfering (si)RNAs from Oilseed rape mosaic tobamovirus (ORMV)-infected Arabidopsis thaliana (Col-0, rdr126, or $d c l 234$ ) at 14 and 22 days postinoculation (dpi). For each plant genotype and timepoint, the histograms plot the numbers of total 20 to 25-nt, 21-nt, or 24-nt viral small (s)RNA reads at each nucleotide position of the 6,303-bp ORMV reference genome sequence (mapped with zero mismatches). The bars above the axis represent sense reads starting at each position and those below represent antisense reads ending at the respective position. A scaled ORMV genome diagram is shown above the histograms, with the open reading frames boxed and their nucleotide positions indicated. The normalization per million of host 21-nt sRNA reads is the most appropriate method for comparison of viral (si)RNA accumulation between wild type (Col-0) and siRNA-deficient (rdr126 and dcl234) Arabidopsis plants. 
defense mechanisms dampen virus replication in the absence of p125 (Supplementary Fig. S1 presents phenotypes and molecular analysis of p125-mutant virus RNAs and proteins in $N$. benthamiana and A. thaliana).
Importantly, in systemic leaves of the mutant virus-infected plants, no reversion of the mutated stop codon was observed at 5 dpi and only a small fraction of viral RNA contained a reverted stop codon at $26 \mathrm{dpi}$. Thus, the p125-deficient virus is

A Percentage of plant genome- and virus-derived 20-25 nt sRNAs in a total $20-25$ nt sRNA population
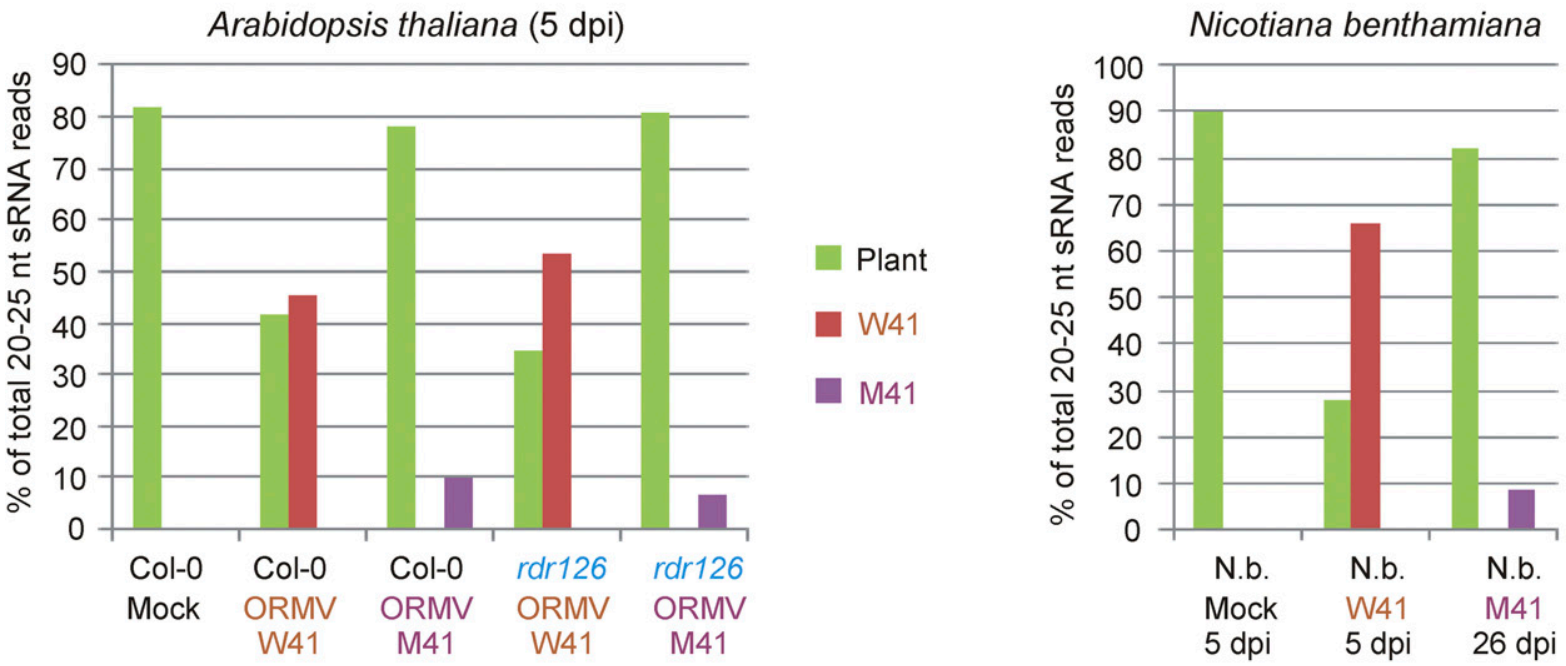

Plant

W41

W41

M41

M41

B Percentage of 20-nt, 21-nt, 22-nt, 23-nt, 24-nt and 25-nt sRNAs in total 20-25 nt sRNA populations of the plant endogenous and viral sRNAs

ORMV viral sRNA size-classes in $A$. thaliana (5 dpi)

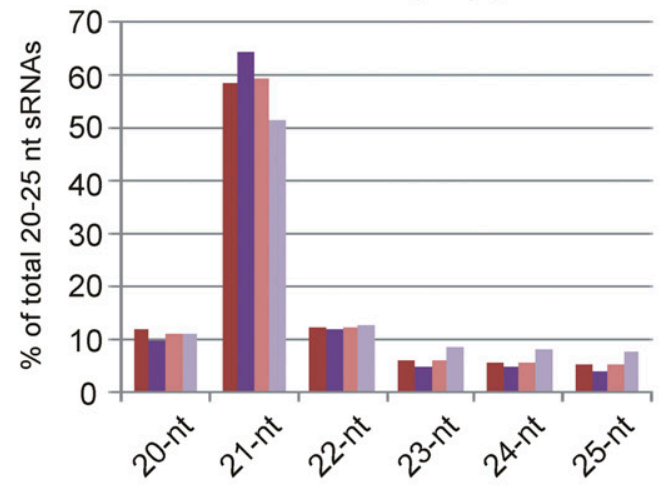

\section{A. thaliana sRNA size-classes (5 dpi)}

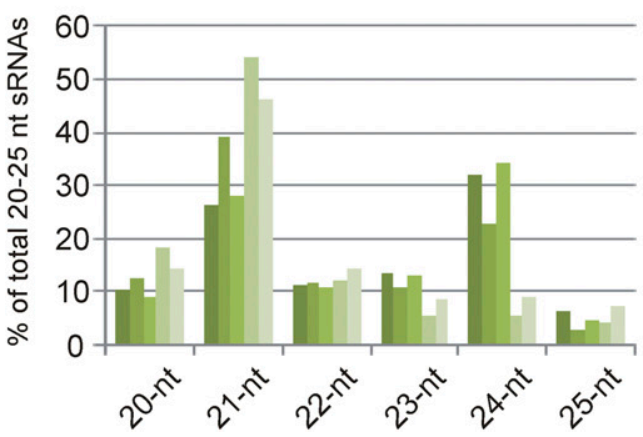

Col-0 W41

Col-0 M41

rdr126 W41

rdr126 M41

Col-0 Mock

Col-0 W41

Col-0 M41

rdr126 W41

rdr126 M41

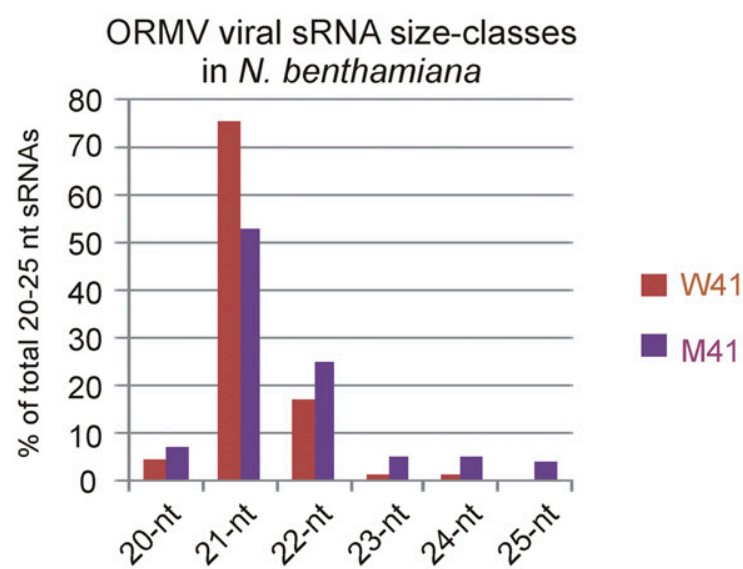

$N$. benthamiana sRNA size-classes

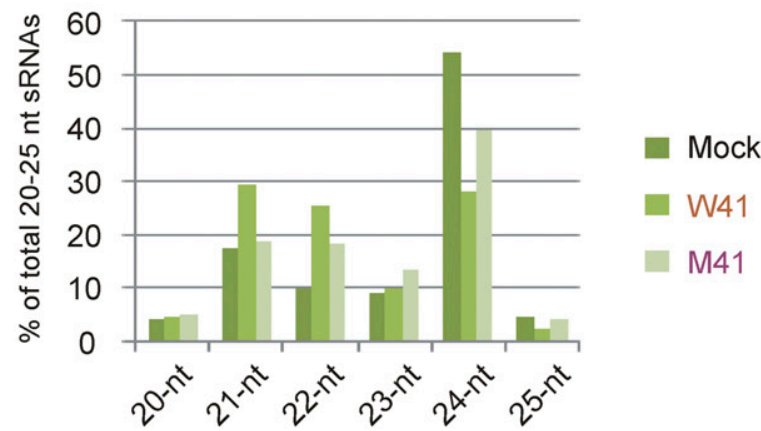

Fig. 4. Illumina sequencing counts of endogenous and viral small (s)RNAs in mock-inoculated and virus (W41 or M41)-infected Arabidopsis thaliana (Col-0 or rdr126) at 5 days postinoculation (dpi) and Nicotiana benthamiana (N.b.) at 5 and 26 dpi. A, Percentages of virus- and plant-derived sRNAs (mapped to Oilseed rape mosaic tobamovirus [ORMV] and plant genome reference sequences with zero mismatches) in the pool of total 20- to 25-nt reads. B, Size class percentages for 20- to 25-nt virus- and plant-derived sRNA reads (mapped with zero mismatches to the corresponding reference sequence). Note that aliquots of the same total RNA samples (extracted from systemic leaf pools of three plants per each condition) was used for both Illumina sequencing and blot hybridization analysis. In the case of $N$. benthamiana, total RNA was extracted from systemic leaf pools of two plants per condition and was analyzed by blot hybridization. 
able to replicate and spread systemically in $N$. benthamiana plants. Nonetheless, in one of the three repeated experiments, there was detectable reversion of the stop codon and restoration of p125 expression in a single M41-inoculated plant, and when the sap of M41- or M4-infected plants was used to inoculate new individuals, p125 expression was quickly restored, leading to rapid death of the hosts. Thus, even though p125 is not essential for ORMV infection in $N$. benthamiana, p125-defficient viruses are eventually overtaken by stop codon revertants, although the process takes place at a much slower rate than in A. thaliana.

\section{ORMV genomic RNA: wild-type W41}

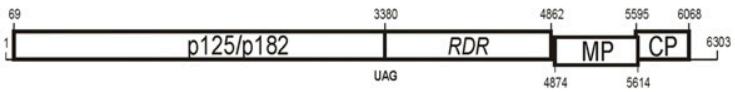

ORMV W41 sRNAs in Col-0 at 5 dpi

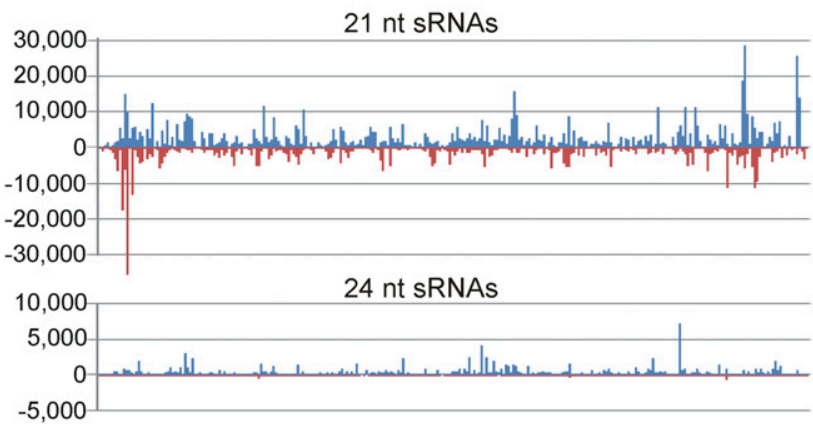

ORMV W41 sRNAs in rdr126 at 5 dpi

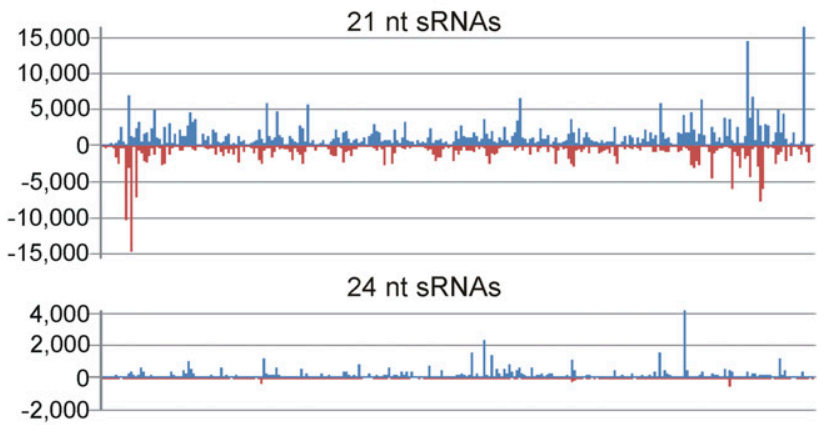

ORMV W41 sRNAs in N.b. at 5 dpi

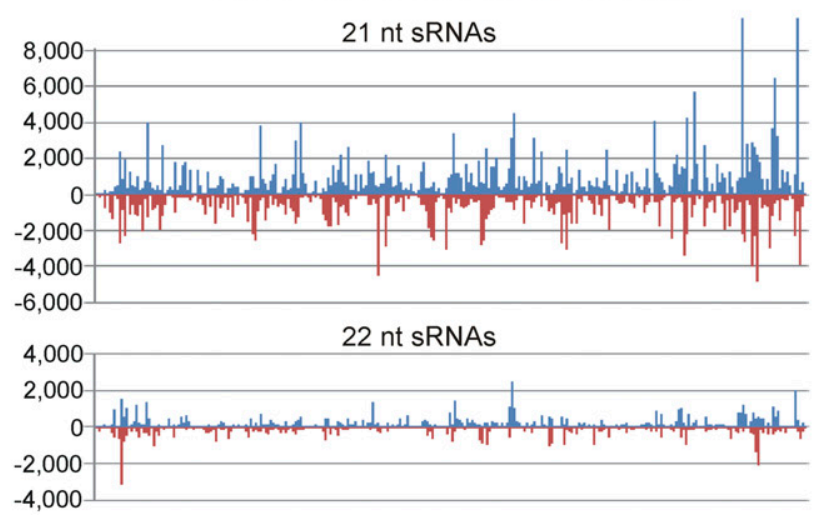

Deep sequencing of sRNAs confirmed that the mutant viruses M41 and M4 did not undergo any substantial reversion of the stop codon at $26 \mathrm{dpi}$ in $N$. benthamiana plants. In wild-type virus (W41)-infected $N$. benthamiana at 5 dpi (before plant death), viral siRNAs were found to be highly abundant, since viral sequences comprise $65 \%$ of total 20 - to 25 -nt reads (Fig. 4A). In contrast, p125-deficient virus-derived siRNAs accumulated to much lower levels at $26 \mathrm{dpi}$ ( 9 and $20 \%$ of total 20- to $25-\mathrm{nt}$ reads for M41 and M4, respectively) (Fig. 4A), which correlates with lower levels of gRNA and sgRNAs. An analysis of
ORMV genomic RNA: mutant M41

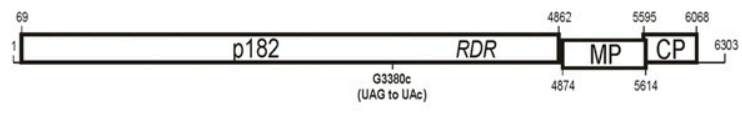

ORMV M41 sRNAs in Col-0 at 5 dpi

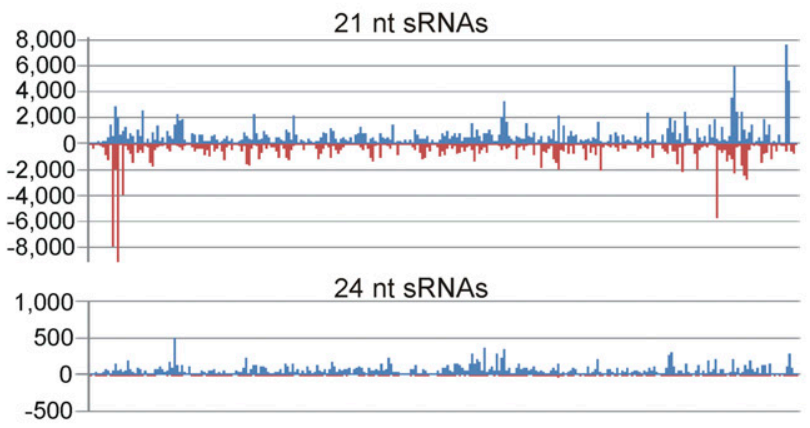

ORMV M41 sRNAs in rdr126 at 5 dpi

$21 \mathrm{nt}$ sRNAs

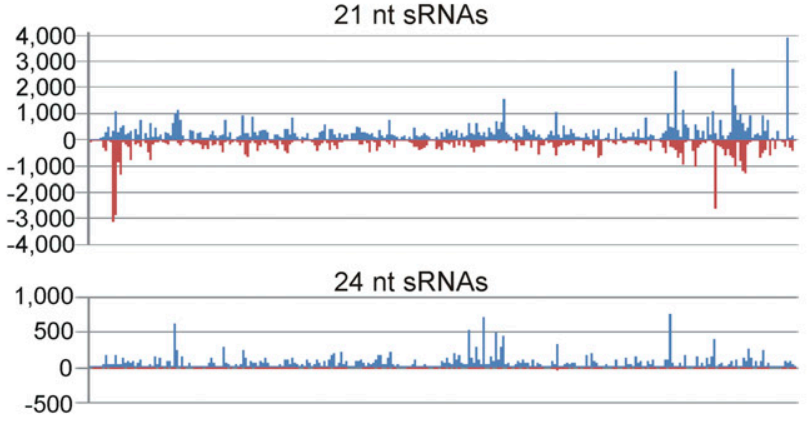

ORMV M41 sRNAs in N.b. at 26 dpi

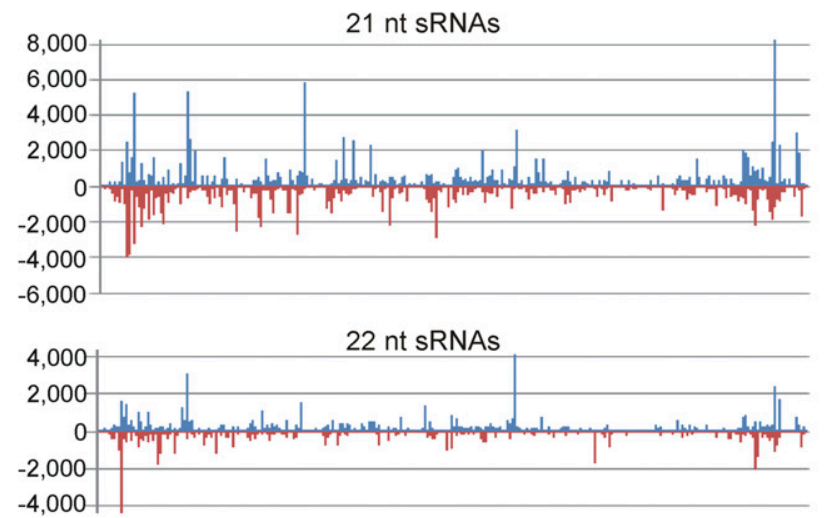

Fig. 5. Single-nucleotide resolution maps of 20- to 25-nt viral (si)RNAs from virus (W41 or M41)-infected Arabidopsis thaliana (Col-0 or $r d r 126)$ at 5 days postinoculation (dpi) and Nicotiana benthamiana (N.b.) at 5 and 26 dpi. For each plant genotype and timepoint, the histograms plot the numbers of total 20- to 25-nt, 21-nt, and 24-nt viral small (s)RNA reads at each nucleotide position of the 6,303-bp W41 or M41 reference genome (mapped with zero mismatches); the bars above the axis represent sense reads starting at each respective position and those below represent antisense reads ending at the respective position. A scaled Oilseed rape mosaic tobamovirus (ORMV) genome diagram is shown above the histograms, with the open reading frames boxed and their nucleotide positions indicated. The normalization per million of host 21-nt sRNA reads is the most appropriate for comparison of viral siRNA accumulation between wild type (Col-0) and siRNA-deficient (rdr126 and dcl234) Arabidopsis plants. 
single-base resolution maps of viral 20- to 25-nt reads (Supplementary Dataset S3) revealed that the two most abundant viral siRNA size classes (21-nt and 22-nt) were equally distributed between both strands alongside the entire virus genome and that siRNA hotspot patterns were similar between M41 and W41 (Fig. 5). Furthermore, 5' terminal nucleotide frequency in viral reads was also comparable between M41 and W41. Thus, despite substantial differences in overall accumulation levels, DCL-mediated processing of viral siRNAs from dsRNA precursors does not appear to be influenced by p125 in $N$. benthamiana, in agreement with our findings for A. thaliana.

\section{p125 interferes with the methylation}

of viral and endogenous SRNAs during ORMV infection.

It has been shown that ORMV interferes with HEN1mediated methylation of viral siRNAs as well as of endogenous
siRNAs and miRNAs in A. thaliana (Akbergenov et al. 2006; Blevins et al. 2006). To test whether 125 is responsible for this effect, we assessed the methylation status of sRNAs from W41and M41-infected plants by a classical $\beta$-elimination method. If RNA is not modified at the $3^{\prime}$ terminal nucleotide, $\beta$-elimination removes it, leaving a truncated RNA with a $3^{\prime}$ phosphate whose mobility in denaturing $15 \%$ polyacrylamide gel electrophoresis (PAGE) is shifted by two nucleotides (Akbergenov et al. 2006) (e.g., nonmethylated 22-nt RNA (+) control in Figure 6). HEN1 methylates plant miRNAs and siRNAs at the $2^{\prime}$ hydroxyl of their $3^{\prime}$ terminal nucleotide, which blocks $\beta$-elimination. As can be observed (Fig. 6), A. thaliana miR168 and miR173, A. thaliana siR255, and $N$. benthamiana miR168 and miR482 are methylated in noninfected plants and, therefore, fully resistant to $\beta$-elimination. In contrast, a significant fraction of viral siRNAs and endogenous sRNAs in wild-type virus (W41)-infected $A$. thaliana and $N$. benthamiana was sensitive to $\beta$-elimination (Fig. 6, lanes 4

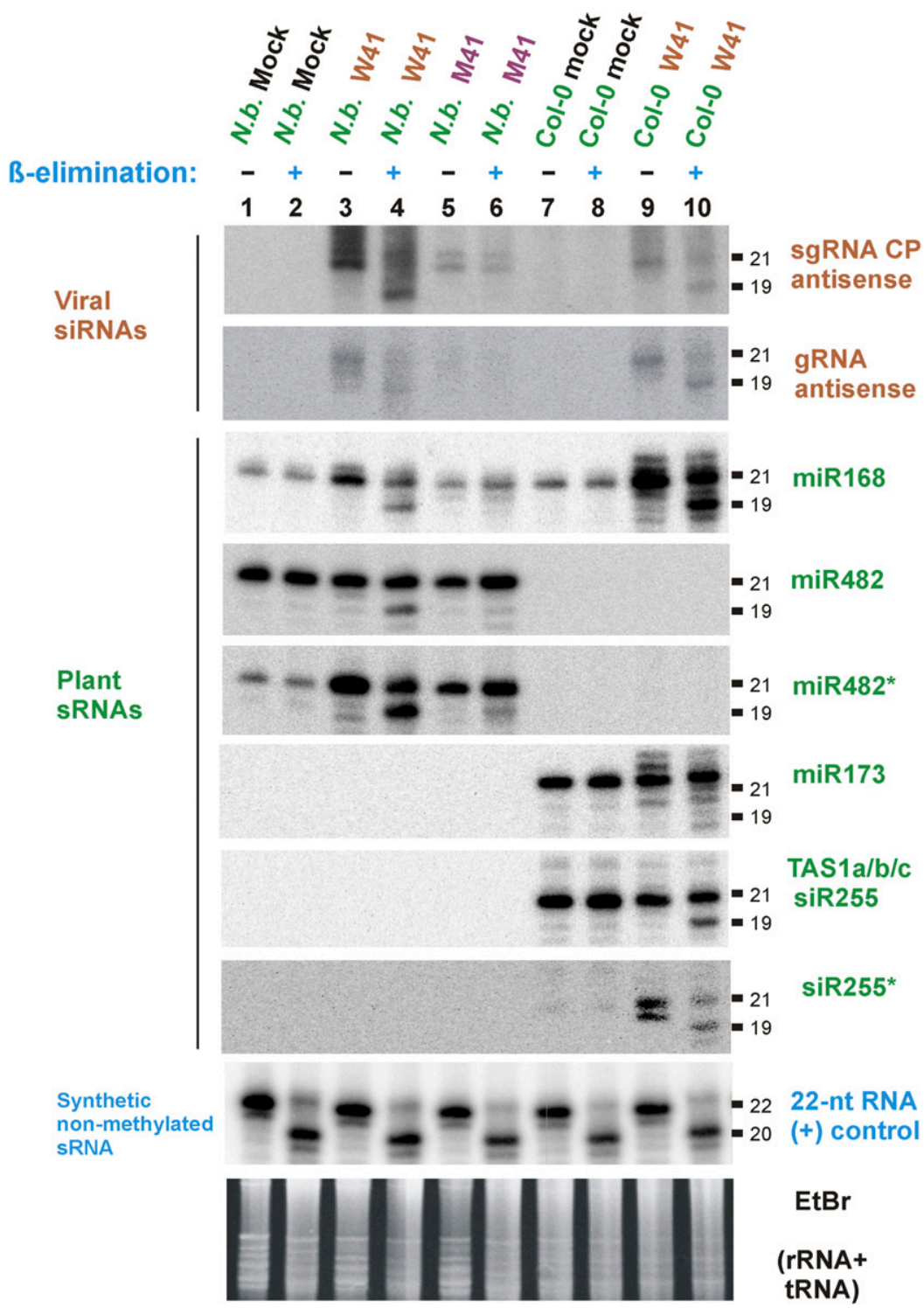

Fig. 6. $\beta$-elimination analysis of viral and endogenous small (s)RNAs in plants infected with wild-type (W41) or p125-deficient (M41) virus. Two aliquots were taken from each total RNA sample from Nicotiana benthamiana (N.b.) systemically infected with W41 (5 days postinoculation [dpi]; systemic leaf pool of two plants) or M41 (26 dpi; systemic leaf pool of two plants) or A. thaliana (Col-0) infected with W41 (22 dpi; systemic leaf pool of three plants). One was treated with periodate $(+)$ and the other with buffer (-) and both were analyzed by $15 \%$ polyacrylamide gel electrophoresis and were blotted. The blot was successively hybridized with DNA oligonucleotide probes specific for viral antisense (si)RNAs derived from Oilseed rape mosaic tobamovirus p125 or coat protein (CP) genes, for plant micro (mi)RNAs (miR168, miR482), miRNA* (miR482*), siRNA (siR255) and siRNA* (siR255*) species, and for a synthetic nonmethylated 22-nt RNA (spiked into each total RNA sample as an internal control). sRNA sizes are indicated on each scan. The ethidium bromide (EtBr)-stained gel is shown as loading control. 
and 10), while both viral and endogenous (miR168 and miR482) sRNAs from $N$. benthamiana plants infected with the mutant virus (M41) were resistant to $\beta$-elimination (Fig. 6, lane 6). This indicates that, in the absence of p125, the virus is not able to block the methylation of viral siRNAs. Taken together, our data indicate that $\mathrm{p} 182$, when expressed in the absence of $\mathrm{p} 125$, does not interfere with HEN1-mediated methylation of viral and endogenous sRNAs. Note that, in the case of $N$. benthamiana, 182 accumulation in the mutant virus-infected plants was comparable to p125 accumulation in the wild-type virus-infected plants.

Although it has been shown that, in A. thaliana HEN1-deficient mutant lines, sRNA accumulation is impaired (Yang et al. 2006; Yu et al. 2005), such a phenomenon was not observed in ORMVinfected plants, where HEN1-mediated methylation is partially inhibited. On the contrary, viral siRNAs and many endogenous sRNAs accumulated to much higher levels in W41-infected plants compared with M41-infected plants, and plants infected with wild-type ORMV produced higher-than-normal levels of nonmethylated passenger strands from endogenous miRNA and siRNA duplexes (Blevins et al. 2006) (Fig. 6).

To ascertain whether sRNA-mediated cleavage and degradation of target mRNAs is affected in ORMV-infected plants, we examined the relative accumulation of $A G O 1$ and $A G O 2$ mRNAs, known to be targeted by miR168 and miR403, respectively. Northern blot hybridization analysis revealed that the levels of these mRNAs were higher in 14- and 22-dpi ORMV-infected plants than in mock-inoculated controls (Fig. 1A). This finding is consistent with a previous transcriptome profiling study, where ORMV infection of Col-0 plants was found to gradually elevate the levels of AGO1 and AGO2 mRNAs at 7, 14, and 21 dpi (Hu et al. 2011). However, a corresponding increase in the levels of the proteins encoded by these mRNAs was not detected by Western blot analysis; rather, the levels of AGO1 had decreased drastically by 15 dpi (Fig. 1G). Hence, despite the apparent compromise of miRNA-directed mRNA cleavage, the translation of target mRNAs appears to be repressed by the overaccumulation of their miRNAs. Indeed, the degree of miR168 overaccumulation upon ORMV infection is much higher than that of miR403 (Fig. 1B), fitting with the much more pronounced drop in the levels of AGO1 compared with AGO2 protein (Fig. 1G). It is worth noting that ORMV-mediated upregulation of miR168 depends on p125, as the p125-deficient virus did not up-regulate this miRNA in $A$. thaliana (Fig. 1D) nor in N. benthamiana (Fig. 6).

\section{Transgenic expression of p125 partially recapitulates viral disease symptoms and impacts on plant sRNAs.}

To verify that p125 is solely responsible for the enhancement of disease symptoms and the impact on sRNA biogenesis in the context of ORMV infections, we engineered transgenic plants expressing p125 and p182, either individually or in combination. To this end, the corresponding coding sequences were subcloned from a full-length ORMV clone or its derivative with the p125 stop codon mutation into the pEarleygate binary vectors 100 (no tag), 201 (hemagglutinin [HA]-tag), and 202 (FLAG-tag) under control of the Cauliflower mosaic virus (CaMV) 35S promoter. The resulting constructs were first tested in a classical transient expression assay in leaves of the $N$. benthamiana green fluorescent protein (GFP) transgenic line $16 \mathrm{c}$ for their ability to suppress GFP transgene-induced silencing and were then used for stable transformation of $A$. thaliana Col0 plants.

Transient expression of p125 or its derivative with an Nterminal FLAG-tag (p125-FG) suppressed GFP silencing as strongly as potyviral helper component proteinase (pHC-Pro) or tombusviral p19, ranked among the strongest silencing suppressors in this system (Hamilton et al. 2002) (Fig. 7B). Blot hybridization analysis revealed that the strong suppression of GFP silencing by p125 and pHC-Pro was not associated with a reduced accumulation of GFP transgene-derived siRNAs of sense or antisense polarities (Fig. 7B), which is consistent with previous research implicating the duplex sRNA-binding activity of both HC-Pro (Garcia-Ruiz et al. 2015) and p125 homologs (Csorba et al. 2007; Kurihara et al. 2007) in silencing suppression. Further supporting this hypothesis, we found that transient expression of either p125, p125-FG, or pHC-Pro increased the accumulation of miR482*, which is normally degraded (Fig. 7B).

Phenotyping of Arabidopsis transgenic lines carrying each of the nine ORMV replicase constructs revealed that the expression of p125 without tags produced strong developmental abnormalities, resulting in adult plants exhibiting serration of the rosette leaf margins and curling of the stem (Fig. 7C). This phenotype, reproducible in $\mathrm{T} 2$ and $\mathrm{T} 3$ progenies of two independent transgenic lines, is remarkably similar to that produced by ORMV infection, the only difference being that the latter produces chlorosis in older leaves (Fig. 7C). The severity of the developmental defects exhibited by p125-transgenic lines was correlated with the accumulation levels of some plant miRNAs (miR168 and miR472) and of the passenger strands of some miRNA (miR472*) and tasiRNA (siR255*) duplexes (Fig. 7E, lanes 2 and 3). Remarkably, these plant sRNAs also accumulated to high levels in ORMV-infected A. thaliana plants (Fig. $1 \mathrm{~B}$ and $\mathrm{D})$. Taken together these findings indicate that $\mathrm{p} 125$ is a strong silencing suppressor that interferes with sRNA biogenesis and plant development.

In contrast to $\mathrm{p} 125$, expression of $\mathrm{p} 182$ alone did not suppress GFP silencing or alter plant phenotype and sRNA accumulation, while expression of $\mathrm{p} 182$ together with $\mathrm{p} 125$ weakened the ability of the latter to suppress GFP silencing and compromise plant development and sRNA biogenesis (Supplementary Fig. S2). However, accumulation of p182 protein was below detection in these assay systems (data not shown), which does not allow for definitive conclusions on the role of p182.

\section{DISCUSSION}

In this work, we investigated the roles of proteins p125 and p182 from the tobamovirus ORMV in viral gRNA replication, sgRNA transcription, and suppression of sRNA-directed antiviral silencing during systemic infection in A. thaliana and $N$. benthamiana. To this end, we constructed a mutant virus expressing exclusively p182 but not p125, by eliminating the stop codon preceding the RDR domain of the former, and tested it for infectivity in both wild-type plants and silencing-mutant plants deficient in DCL- and RDR-dependent siRNA biogenesis. Furthermore, we examined the effects of both viral proteins, alone or in combination, on the plant sRNA-generating silencing machinery during their transient expression in $N$. benthamiana leaves and upon stable constitutive expression in Arabidopsis transgenic lines.

\section{Functions of p125 and p182}

in viral replication versus silencing suppression.

Our analysis of the p125-deficient mutant virus in systemic leaf tissues of $A$. thaliana and $N$. benthamiana revealed that p125 is not essential for gRNA replication or sgRNA transcription. However, gRNA and sgRNAs of the p125-deficient mutant accumulated to levels lower than those of the wild-type virus (Fig. 1C) and stop codon revertants often accumulated and overtook the mutant population, restoring p125 expression (Fig. 1F). These findings are consistent with previous observations in other tobamoviruses, in which mutants expressing exclusively the readthrough replicase do replicate in tobacco protoplasts and plant tissues, albeit with a reduced efficiency, 
and stop codon revertants restoring expression of the shorter protein appear at a high frequency (Ishikawa et al. 1986; Knapp et al. 2001; Lewandowski and Dawson 2000).

Theoretically, p125 can facilitate one or both viral replication and transcription, either indirectly, through its silencing suppressor activity, or directly, through the formation of a putative heterodimer with $\mathrm{p} 182$. In other tobamoviruses, the replicase and guanylyltransferase enzyme activities localize to membranebound heterodimers of the corresponding p125/p182 homologs (Hagiwara et al. 2003; Komoda et al. 2007; Nishikiori et al. 2012; Osman and Buck 1996; Watanabe et al. 1999), and leftover p125, which is present at molar excess, forms oligomers (Watanabe et al. 1999), which might assume additional roles unrelated to viral gRNA replication and sgRNA transcription. Indeed, non-membrane-bound fractions of the tobamoviral replication proteins have been implicated in silencing suppression via their sRNA binding activities (Hagiwara-Komoda et al. 2008). Here, we demonstrate that p125 is a strong silencing suppressor in the classical transient expression assay in $N$. benthamiana $16 \mathrm{c}$ plants (Fig. 7B) and that p125 is required for the inhibition of HEN1 activity during ORMV infection (Fig. 6). We favor a scenario in which p125 facilitates viral replication and transcription only indirectly, through its anti-silencing activity. In support of this hypothesis, the replication of evolutionarily related potexviruses in the alpha-like virus supergroup, such as Potato virus X, require only one virus-encoded protein $(\mathrm{P} 1)$ that

\section{A ORMV p125 construct}

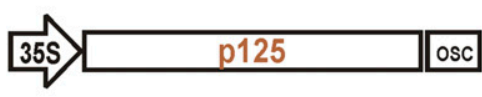

\section{B Transient expression in N.benthamiana leaves}

Relative GFP fluorescence

\begin{tabular}{ll}
\hline Empty & - \\
p125 & ++++ \\
pHC-Pro / p19 & ++++ \\
\hline
\end{tabular}

Small RNA blot hybridization

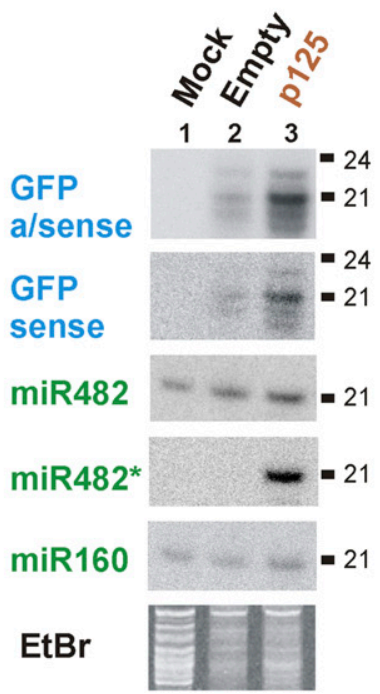

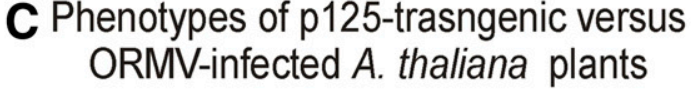

p125-transgenic

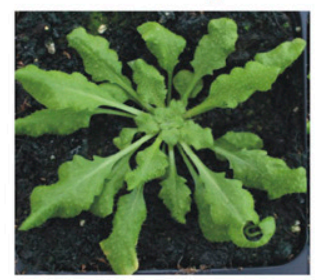

Before bolting

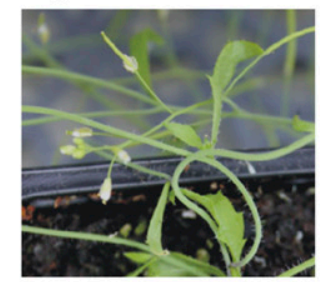

After bolting

ORMV-infected

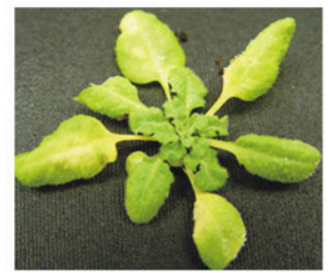

Inoculated early

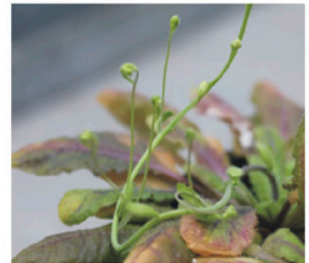

Inoculated late

\section{Western blot analysis}

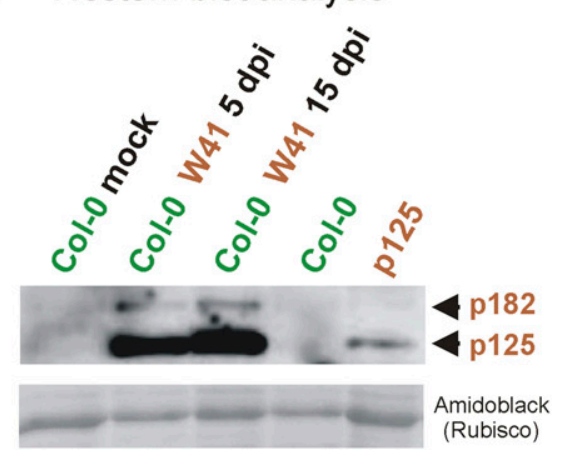

E Small RNA analysis of A. thaliana transgenics

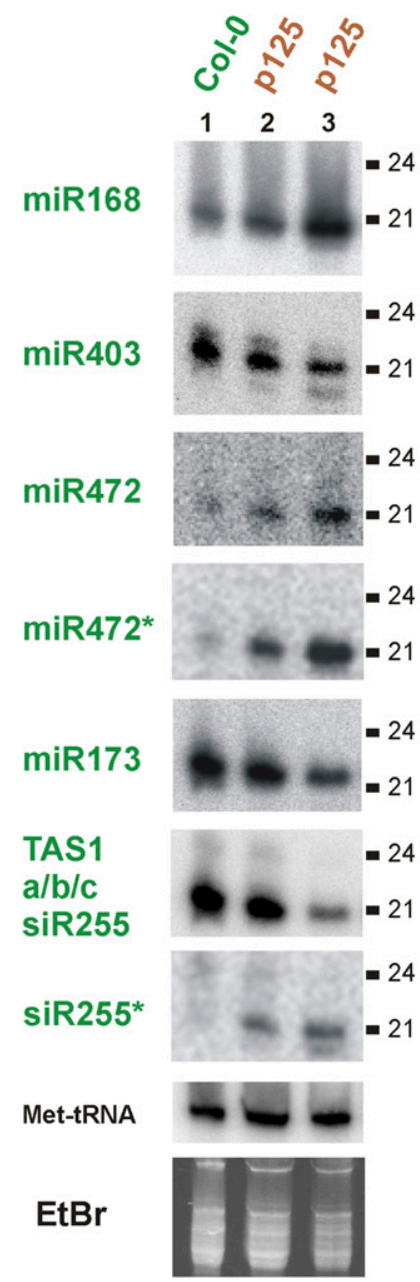

Fig. 7. Transgenic expression of p125 alone partially recapitulates viral disease symptoms and the impact of viral infection on plant small (s)RNAs. A, Schematic representation of a pEarleygate expression construct carrying Oilseed rape mosaic tobamovirus (ORMV) p125 coding sequence under control of the Cauliflower mosaic virus $35 \mathrm{~S}$ promoter and octopine synthase terminator. B, Effects of transient expression of the ORMV p125, pHC-Pro, or p19 constructs on transgene-induced silencing (measured as relative green fluorescent protein [GFP] fluorescence) and the accumulation of GFP short interfering(si)RNAs and plant micro (mi)RNAs (examined by sRNA blot hybridization at 10 days postinoculation [dpi]) in Nicotiana benthamiana GFP transgenic 16c plants. The sRNA blot was successively hybridized with DNA oligonucleotide probes specific for GFP sense and antisense siRNAs and plant miR482, mi160, and miR482*. sRNA sizes are indicated. The ethidium bromide (EtBr)-stained gel is shown as a loading control. C, Representative phenotypes of the p125transgenic plants (T2 plants of line 32) before and after bolting, compared with ORMV-infected A. thaliana Col-0 plants (the rosette leaves following early inoculation and the stem following late inoculation). D, Western blotting analysis of viral p125 and p182 proteins in Arabidopsis Col-0 plants infected with ORMV (W41) at 5 and 15 dpi and in Arabidopsis transgenic plants carrying the p125 (T3-plant of line 33) construct. The membrane was incubated with an antip125 antibody or was stained with Amido Black, shown here as loading control (Rubisco). The expected positions of p125 and p182 are indicated with arrowheads. E, sRNA blot hybridization analysis (15\% polyacrylamide gel electrophoresis) of total RNA samples from two individual plants of the Arabidopsis transgenic line carrying the p125 expression construct (two T3 plants of line 32, lanes 2 and 3) or the control wild-type plant (Col-0; lane 1). The blot was successively hybridized with DNA oligonucleotide probes specific for plant miR168, miR403, miR173, miR472*, siR255, and siR255* and for Met-tRNA. sRNA sizes are indicated on each scan. The EtBr-stained gel is shown as loading control. 
is equivalent to the tobamoviral readthrough replicase, and the silencing suppressor activity resides in a separate viral gene (p25) (Bayne et al. 2005). Our data do not support an essential direct role of p125 in ORMV replication, as the p125-deficient virus was clearly able to infect systemically the entire plant without reverting the stop codon at $5 \mathrm{dpi}$ in A. thaliana (Fig. 1C and $\mathrm{F}$; and the sRNA sequencing analysis showing no reversion) and up to $26 \mathrm{dpi}$ in $N$. benthamiana (the sRNA sequencing analysis showing no reversion). Hence, p125 is not essential for viral replication, cell-to-cell movement through plasmodesmata, or systemic movement via vascular tissues. It should be noted, however, that our results do not rule out a possibility that p125 may facilitate viral replication by forming a heterodimer with $\mathrm{p} 182$.

Unlike p125, the readthrough replicase p182 does not appear to possess any silencing suppressor activity. The most compelling evidence for the inability of p182 to suppress antiviral silencing comes from the molecular analysis of virus-derived sRNAs; the p125-deficient mutant virus was not able to interfere with HEN1-mediated methylation of viral siRNAs and plant sRNAs in systemically infected $N$. benthamiana plants (Fig. 6), in which p182 accumulation was detectable and comparable to 125 accumulation in wild-type virus-infected plants. Additionally, we did not suppression of GFP silencing or impacts on plant small RNAs when we attempted to express the p182 protein transiently or stably, although we did not observe expression of the protein by Western blotting with anti-p125 antibody (data not shown).

Why is it that $\mathrm{p} 182$, containing the entire $\mathrm{p} 125$ polypeptide, is not able to suppress silencing? The C-terminal RDR domain of p182, which is missing in p125, may plausibly inhibit a potential anti-silencing activity residing elsewhere on the protein. Moreover, p125-mediated suppression of antiviral silencing likely takes place in the cytoplasm, in which soluble p125 may bind sRNA duplexes and interfere with the activity of HEN1, preventing RISC assembly. Being localized in a membrane-bound replication complex, p182 may not be available for other functions, unless it is overexpressed. During viral infection, p125 is produced in an approximately ten-toone molar excess over p182 (Fig. 1F), which would ensure that sufficient p125 is available in the cytoplasm to exert its antisilencing activity. p125 is likely the first viral protein to be translated from gRNA in a virus-infected cell, followed by 182 via p125 stop codon readthrough and, then, by replication of the gRNA from which both p125 and 182 were translated. It is tempting to speculate that the overexpression of p125 at the earliest stage of the viral replication cycle has the primary objective of ensuring that any primary viral siRNAs arising from the processing of gRNA replication and sgRNA transcription dsRNA intermediates by DCL activities are promptly bound and sequestered.

\section{The biogenesis of viral siRNAs in ORMV-infected plants.}

Our data from deep sequencing of viral siRNAs (Figs. 2, 3, 4, and 5) and blot hybridization (Fig. 1) support the hypothesis that viral dsRNA replication and transcription intermediates, which span the entire ORMV genome, are already targeted by DCLs at the early stages of viral infection. First, both gRNA and $\mathrm{gRNA}(-)$ as well as sgRNA-CP and $\mathrm{CP}(-)$ accumulate to higher than wild-type levels at $5 \mathrm{dpi}$ in A. thaliana dcl234 (Fig. 1C), in which viral siRNA generation is impaired. Second, the population of virus-derived siRNAs in wild-type A. thaliana or $N$. benthamiana does not exhibit any site preference or strand bias throughout the ORMV genome, and this viral siRNA profile remains unaltered in Arabidopsis rdr126 plants lacking functional RDR activities (Figs. 2, 3, 4, and 5). Thus, DCLs appear to use directly dsRNA intermediates of viral gRNA replication (and possibly sgRNA transcription) for their processing into siRNAs. A similar mechanism whereby DCL directly process viral dsRNA replication intermediates has previously been proposed, not only for other positive-sense plant RNA viruses such as the potyvirus TuMV (Garcia-Ruiz et al. 2010) and the cucumovirus CMV (Wang et al. 2010, 2011), but even for a positive-sense RNA virus in Drosophila melanogaster, in which RDR genes do not exist (Flynt et al. 2009).

The analysis of the genetic requirements for viral siRNA biogenesis in ORMV-infected A. thaliana (Blevins et al. 2006; this study), coupled with viral sRNA profiling by deep sequencing in this study, confirms the notion that DCL4 is the primary antiviral dicer producing 21-nt viral siRNAs in this host, while DCL2 and DCL3 assume the role of secondary dicers producing 22-nt and 24-nt viral siRNAs, respectively, in the absence of DCL4 activity (Blevins et al. 2006; Bouché et al. 2006; Fusaro et al. 2006; Xie et al. 2004). Surprisingly, the comparative analysis performed here between ORMV-infected Col- 0 and $d c l 234$ plants revealed a strong positive-strand bias in $d c l 234$ for all major sRNA size classes except for the 21-nt class, in which a much weaker bias was observed (Fig. 3). A strong positive-strand bias was observed in Col-0 only for minor size classes such as the 24-nt class (Fig. 3). This finding implies that, in $d c l 234$, viral dsRNAs are processed into 21-nt siRNA duplexes, presumably by DCL1, whereas viral singlestranded RNAs of positive sense polarity, i.e., $\operatorname{gRNA}(+)$ and sgRNAs, give rise to single-stranded sRNAs of all sizes, presumably through random cleavage by DCL1 or one or more other RNase III-like endonucleases. The processing of ORMV siRNA precursors in $d c l 234$ plants, whether by DCL1 or another RNase III-like activity, appears to be less efficient and precise, giving rise to sRNAs of a broader size range with a strong positive-strand bias in addition to 21-nt siRNA duplexes (Figs. 2B and 3). DCL1 has previously been shown to be involved in viral siRNA biogenesis for the DNA viruses Cabbage leaf curl geminivirus (Aregger et al. 2012; Blevins et al. 2006) and Cauliflower mosaic pararetrovirus (Blevins et al. 2006, 2011), using A. thaliana triple and quadruple $d c l$ mutants. Notably, in the latter case, DCL1 produced a major fraction of 21-nt siRNAs from a viral dsRNA decoy (Blevins et al. 2011). A candidate RNase III-like activity that might also process ORMV siRNA precursors would be RTL1 or other members of the recently characterized A. thaliana RTL1 gene family (Elvira-Matelot et al. 2016; Shamandi et al. 2015). Interestingly, RTL1 can be induced by viral infection and inactivated by viral silencing suppressors, and its transgenic overexpression in A. thaliana interferes with the activity of DCL2, DCL3, and DCL4 by targeting their endogenous dsRNA substrates (Shamandi et al. 2015).

A strong sense strand bias has been previously reported for viral siRNAs produced in wild-type plants infected with some positive sense RNA viruses, leading to the hypothesis that the main substrates for DCL4 and other DCLs are secondary structures formed by viral RNAs (Molnár et al. 2005). Our findings in ORMV-infected Arabidopsis wild-type and rdr126 plants at 5,14 , or 22 dpi and $N$. benthamiana plants at 5 or $26 \mathrm{dpi}$, along with previous findings for ORMV- and TMVinfected Arabidopsis plants at 2 and 4 dpi (Zavallo et al. 2015), do not support this hypothesis. However, we found that ORMVinfected Arabidopsis dcl234 plants do exhibit a strong positivestrand bias. Perhaps the inactivation of the siRNA-generating DCLs by viral suppressors may unmask DCL1 or another RNase III-like enzyme that randomly cleaves abundant viral singlestranded RNAs of positive-sense polarity, although such bias might also arise from technical issues with certain sRNA cloning, sequencing, and detection protocols (Harris et al. 2015; Smith et al. 2010). 
Our analysis of wild-type and p125-deficient viruses in Col-0 and $r d r 126$ plants suggests that neither RDR1, RDR2, nor RDR6 are directly involved in the process whereby viral dsRNA gets processed into siRNAs, implying that most ORMV-derived siRNAs are primary, RDR-independent species. It should be noted, though, that, despite the similar viral siRNA profiles of Col-0 and rdrl26 plants (Figs. 2, 3, 4, and 5), the latter exhibited higher levels of wild-type ORMV gRNA by the late stages of infection (Fig. 1A), suggesting that RDR-dependent secondary siRNAs may contribute to defense against the wildtype virus. Earlier studies of suppressor-deficient mutants of RNA viruses CMV and TuMV in Col- 0 versus $r d r$ mutant plants revealed one or both RDR1- and RDR6-dependent secondary viral siRNAs restricting replication and systemic infection of the mutant viruses (Garcia-Ruiz et al. 2010; Wang et al. 2010, 2011). In the present case, however, the lack of substantial differences between Col-0 and $r d r 126$ plants regarding global and local profiles of viral siRNA sizes, 5' nucleotide identities, and hot spots along the wild type or p125mutant ORMV genome indicates that RDR1 and RDR6 may not contribute to viral siRNA biogenesis, although the quantitative differences in viral siRNA accumulation were observed. Presumably the absence of RDR activities facilitates ORMV replication only indirectly, through the loss of endogenous plant siRNAs such as tasiRNAs and heterochromatic siRNAs that may normally downregulate the expression of gene products that facilitate viral replication. Still, it should be noted that replication of the p125-deficient virus was not facilitated in rdr126 compared with Col-0 plants (Fig. 1C). An interesting possibility would be that, in the absence of functional RDRs, p125-deficient virus might be preferentially targeted by an RNA decay mechanism known to compete with RDRs for aberrant RNA substrates (Christie et al. 2011). In line with this hypothesis, both TMV infection and transgenic expression of TMV MP or CP genes induce the plant RNA decay genes (Conti et al. 2017).

\section{Effect of p125 on the production, modification, and activity of viral siRNAs and plant siRNAs and miRNAs.}

By comparing wild-type and p125-deficient mutant viruses, we demonstrated that p125 does not block the production of viral siRNAs; rather, viral siRNAs are produced at much higher levels in the presence of p125, concomitant with higher levels of viral gRNA replication, sgRNA transcription, and increased disease severity. This suggests that virus-derived sRNAs are failing to restrict viral replication and transcription. We found that, in the presence of $\mathrm{p} 125$, viral siRNAs become sensitive to $\beta$-elimination, although this does not lead to their destabilization, as expected based on the fact that endogenous siRNAs become unstable in Arabidopsis mutant lines lacking HEN1 (Yang et al. 2006; Yu et al. 2005). The observed stability of $\beta$-elimination-sensitive viral siRNAs during infection with wild-type ORMV may arise from the binding of siRNA duplexes by p125, which would, in turn, prevent HEN1-mediated methylation, prevent the formation of RISCs, and thus, interfere with either siRNA-directed cleavage, translational repression of viral RNAs, or both, as has been proposed for $\mathrm{p} 122$, a p125 homolog from crucifer-infecting TMV (Csorba et al. 2007). Still, we do not have any direct evidence supporting this hypothesis. On the contrary, what indirect evidence we do have, based on the analysis of $A G O 1$ and $A G O 2$ gene expression in ORMV-infected plants, indicates that an increased accumulation of miR168 and miR403 actually leads to translational repression of their target mRNAs ( $A G O 1$ and $A G O 2$, respectively) despite higher-than-normal levels of the latter (Fig. 1A and G). Concomitant increases in the levels of miR168 and
AGO1 mRNA accompanied by a drop in the levels of AGO1 protein have previously been observed during infections of A. thaliana with different RNA viruses, including the cruciferous strain of TMV (Várallyay et al. 2010, 2013), so our data extend these findings to ORMV and demonstrate that p125 is responsible for the perturbation of miR168 and AGO1 expression during ORMV infection. The induction of miR168 and miR403 mediated by p125 can be part of a viral counterdefense strategy to repress AGO1 and AGO2 translation and thus prevent the formation of viral siRNA-AGO1 and viral siRNA-AGO2 complexes, whose involvement in antiviral defense is well documented (Carbonell et al. 2012; Garcia-Ruiz et al. 2015; Wang et al. 2011). The increased accumulation of $A G O 1$ and $A G O 2$ mRNAs observed at later stages of ORMV infection (Fig. 1A) is likely part of a plant counter counterdefense strategy involving a feedback regulation loop to restore and maintain normal levels of AGO1 and AGO2 proteins.

Transcriptome profiling of ORMV-infected Col- 0 plants at 7 , 14 , and 21 dpi during a previous study revealed a general upregulation of cellular mRNAs targeted by miRNAs, tasiRNAs, or both, concomitant with an increased accumulation of their respective miRNAs and tasiRNAs (Hu et al. 2011). This major perturbation of the host miRNA and siRNA pathways, triggered by p125, as we established here, may constitute a contributing factor for the development of the severe disease symptoms that characterize the later stages of ORMV infection. Indeed, our analysis of Arabidopsis transgenic lines carrying p125, p182, or p125/182 constructs revealed that $\mathrm{p} 125$ expression partially recapitulates viral disease symptoms, such as serration of the rosette leaves and curling of the stem (Fig. 7C). This is consistent with previous studies demonstrating that the transgenic expression of viral suppressors from different viruses causes developmental abnormalities in Arabidopsis, accompanied by major perturbations of its miRNA and siRNA pathways (Chapman et al. 2004; Shivaprasad et al. 2008).

The analysis of p125-transgenic lines and plants infected with either wild-type or p125-deficient viruses indicates that, in addition to the abovementioned miR168 and miR403, other miRNA and miRNA* species are induced in a p125-dependent manner. One particularly important example is miR472 (Fig. $1 \mathrm{~B}$ and $\mathrm{D})$, which has been shown to regulate plant innate immunity against nonviral pathogens (Boccara et al. 2015). Because pattern-triggered immunity (PTI) has been implicated in antiviral defense (Kørner et al. 2013; Nicaise and Candresse 2017; Niehl et al. 2016) and a viral silencing suppressor protein has been shown to suppress PTI and other immune responses in virus-infected A. thaliana (Zvereva et al. 2016), it is conceivable that p125 may also suppress immune responses. As proposed earlier (Zvereva and Pooggin 2012), such an activity might trigger plant counter counter-defense responses resembling those of effector-triggered immunity (ETI), typically aimed at nonviral pathogens. p125-mediated induction of miR472 would, thus, downregulate ETI-related genes, contributing to suppression of antiviral ETI. Whether p125mediated HEN1 suppression and p125-triggered perturbations of the plant sRNA-directed silencing pathways (including those that regulate immune responses) stem from a significant contribution of PTI to plant defenses against ORMV and whether p125 is directly involved in PTI suppression constitute, therefore, valuable avenues of research. It is worth pointing out that even in $d c l 234$ and $r d r 126$ plants, where major components of the RNA silencing machinery are missing, stop codon revertants in which p125 expression is restored are quickly selected during infections with p125-deficient ORMV mutants, indicating the presence of a selective pressure for this effector imposed by other defense pathways, such as those of plant innate immunity. On the other hand, no differences regarding 
susceptibility to infection with either wild-type or p125deficient ORMV mutants were noticeable in our preliminary experiments with $A$. thaliana mutants lacking BAK1, a major PTI response coreceptor, thus contradicting a previous study (Kørner et al. 2013) while supporting a more recent observation (Nicaise and Candresse 2017). In either case, RNA silencing and innate immunity work in concert to restrict viral replication and systemic movement (Zvereva and Pooggin 2012), so that relieving the selection pressure for p125 expression may require suppressing the activities of both PTI and the siRNA silencing pathways.

\section{MATERIALS AND METHODS}

\section{Construction of an ORMV wild-type infectious clone and its derivatives.}

A plasmid pORMV (provided by F. Ponz and designated here as $\mathrm{W}$ ), containing a full-length cDNA of the ORMV genome (Aguilar et al. 1996) downstream from a T7 promoter, was used as a template for site-directed mutagenesis to replace the p125 amber stop codon TAG with a tyrosine codon TAC as follows. Two overlapping PCR products (662 and $248 \mathrm{bp}$ ), each containing the TAC codon, were separately amplified using primer pair p180_ClaI_s and p126_stop_sup_as and primer pair p126_stop_sup_s and p180_XmaIII_as (Supplementary Table S1 lists all PCR primer sequences and oligonucleotide probes used for blot hybridizations). The resulting PCR products were used for "PCR ligation" with the flanking primers (p180_ClaI_s and p180_Xma III_as). The resulting product (881 bp) containing the TAC mutation was gel-purified, was trimmed with $\mathrm{ClaI}$ and XmaIII restriction enzymes (New England Biolabs) at the sites located in the flanking primers, and was cloned between the ClaI and XmaIII sites of pORMV, replacing the wild-type ORMV sequence. The resulting mutant clone (designated as $\mathrm{M}$ ) was selected following transformation of Escherichia coli DH5 $\alpha$ cells and was sequenced to confirm the presence of the introduced mutation.

As the available pORMV clone $\mathrm{W}$ did not display wild-type disease symptoms, we sequenced sRNAs from A. thaliana Col0 plants infected with ORMV virions and reconstructed, de novo, a 6,303-nt consensus master sequence of the ORMV genome as a single sRNA contig from two independent sRNA libraries (Seguin et al. 2014). The reconstructed sequence differed from the ORMV cDNA sequence at three positions (G-toA at position 12, A-to-T at position 231, and G-to-T at position 5612). To correct these errors, two synthetic DNA fragments (Eurofins) with suitable restriction sites were used to obtain a new wild-type ORMV genome clone, designated W41 (deposited into the National Center for Biotechnology Information GenBank as KF137561). Briefly, the original clone W was digested with EcoNI and NarI in order to replace a 418-bp fragment comprising the $\mathrm{T} 7$ promoter and the adjacent ORMV sequence with a synthetic fragment containing an $\mathrm{A}$ at position 12 and a $\mathrm{T}$ at position 231 . This partially repaired clone, named W4, was then digested with $N c o$ I and PstI to replace a $1-\mathrm{Kb} 3^{\prime}$ portion of the ORMV cDNA with a synthetic fragment containing a $\mathrm{T}$ at position 5612 and a new NsiI restriction site adjacent to the ORMV sequence and followed by the PstI site. This fully repaired clone, named W41, was tested for infectivity in $N$. benthamiana and was found to be biologically active, causing disease symptoms indistinguishable from those of wildtype ORMV (Seguin et al. 2014). A third partially repaired clone was also obtained, designated $\mathrm{W} 1$, after digestion of the original clone W with $N c o$ I and PstI to replace, exclusively, the $1-\mathrm{Kb}$ fragment as described above. The same procedure was followed in parallel to repair the p125 stop codon mutant clone M, yielding the constructs M4, M41, and M1, respectively. All the constructs were sequenced to confirm the introduced mutations and corrections and then tested for infectivity in $N$. benthamiana. The results revealed that the corrections in the $5^{\prime}$ portion of the ORMV genome present in clones W4 and W41 had fully restored infectivity and disease severity, while the correction in the $3^{\prime}$ portion of the genome had only a minor effect. Interestingly, the latter correction (position 5612) mutated the MP ORF stop codon, thereby elongating viral MP by an additional 19 amino acids.

\section{Plant growth and virus inoculation.}

Plants of A. thaliana genotype Col-0 and its mutant or transgenic derivatives were grown in light chambers (Sanyo) at $20^{\circ} \mathrm{C}$ under a 12 -h-light and 12 -h-dark cycle. $N$. benthamiana plants were grown in soil at 20 to $25^{\circ} \mathrm{C}$ in an open greenhouse or in Sanyo chambers at $25^{\circ} \mathrm{C}$, also under a 12-h-light and 12-hdark cycle.

Five weeks postgermination A. thaliana seedlings (three per genotype) were inoculated mechanically with sap from wildtype ORMV-infected N. benthamiana (Akbergenov et al. 2006) or with in vitro RNA transcripts from the ORMV clones described above. Briefly, the sap was distributed onto two leaves per plant $(10 \mu \mathrm{l}$ per leaf) and was mixed with a pinch of Celite 545 (Merck). After rubbing the mix softly with a finger against the upper surface of the leaves, the plants were returned to the light chamber under controlled conditions. The in vitro transcripts were obtained from plasmid DNA of the ORMV constructs (W41, W4, M41, and M4), using the T7 Megascript kit (Ambion) and the cap analog $\mathrm{m} 7 \mathrm{G}\left(5^{\prime}\right) \mathrm{ppp}\left(5^{\prime}\right) \mathrm{G}$ (Ambion), following the manufacturer's instructions. Briefly, for a $20-\mu \mathrm{l}$ reaction, $2 \mu$ of ATP, CTP, and UTP (75 mM each) were added to $1 \mu \mathrm{g}$ of plasmid DNA, were resuspended in $4 \mu \mathrm{l}$ of diethyl pyrocarbonate (DEPC)-treated water. Then, $3 \mu \mathrm{l}$ of the cap analog $(6 \mathrm{mM})$ and $2 \mu \mathrm{l}$ of GTP $(15 \mathrm{mM})$ were added, to promote capping of the transcripts, as well as $2 \mu \mathrm{l}$ of $10 \times \mathrm{T} 7$ reaction buffer, $2 \mu \mathrm{l}$ of T7 enzyme mix, and $1 \mu \mathrm{l}$ of RNase inhibitor RNasin (40 units/ $\mu$ l) (Promega). After a 2-h incubation at $37^{\circ} \mathrm{C}, 1 \mu \mathrm{GTP}(75 \mathrm{mM})$ was added to the mix and was left at $37^{\circ} \mathrm{C}$ for $2 \mathrm{~h}$. Before inoculation, the reaction was diluted $1: 4$ with DEPC-treated water, a $20-\mu$ l aliquot was used as inoculum and another $20-\mu \mathrm{l}$ aliquot was analyzed by agarose gel electrophoresis. Interestingly, the use of linearized (at the introduced NsiI or PstI site) or nonlinearized ORMV plasmid templates for in vitro transcription had no detectable effects on the relative infectivity of the resulting transcripts in planta. We speculate that the artificial tails added in vitro to the $3^{\prime}$ end of the tobamoviral gRNA transcript might be removed by a plant $3^{\prime}$ to $5^{\prime}$ exonucleolytic activity that is stalled by the secondary structure of the transfer RNA-like sequence located at the $3^{\prime}$ terminus of the tobamoviral genome.

\section{Western blotting.}

Systemic (noninoculated) leaves from three plants of $A$. thaliana or two plants of $N$. benthamiana were pooled and were ground in liquid nitrogen (in some cases with $N$. benthamiana and the mutant virus, the leaves were ground individually). Thirty milligrams of ground frozen material were resuspended in $150 \mu$ of $6 \times$ Laemmli sodium dodecyl sulfate (SDS)-PAGE sample loading buffer $(0.35 \mathrm{M}$ Tris- $\mathrm{HCl}, \mathrm{pH} 6.8,22.4 \%$ glycerol, 10\% SDS, $0.6 \mathrm{M}$ dithiothreitol [DTT], bromophenol), were vortexed briefly, and were heated for $3 \mathrm{~min}$ at $95^{\circ} \mathrm{C}$. The samples were vortexed again briefly and were centrifuged at $12,000 \times g$ for $2 \mathrm{~min}$. Aliquots $(12 \mu \mathrm{l})$ of the supernatants were loaded in a $9 \%$ SDS-PAGE gel with a $4 \%$ stacking gel in a Mini-PROTEAN tetra cell (BioRad). Five microliters of PageRuler Plus prestained protein ladder (Thermo Fisher Scientific) were loaded as a molecular weight reference. After gel electrophoresis for $1 \mathrm{~h}$ at $100 \mathrm{~V}$ in Tris-glycine buffer, $\mathrm{pH}$ 
8.3 (25 mM Tris-HCl, $250 \mathrm{mM}$ glycine, $0.1 \% \mathrm{SDS}$ ), the proteins were transferred to an Amersham Hybond-P polyvinylidene diflouride membrane, $0.45 \mu \mathrm{m}$ (GE Healthcare), for $2 \mathrm{~h}$ in the presence of transfer buffer $(25 \mathrm{mM}$ Tris- $\mathrm{HCl}, \mathrm{pH}$ $8.3,192 \mathrm{mM}$ glycine, $0.025 \%$ SDS, $20 \%$ ethanol). The membrane was blocked at room temperature with $1 \%$ bovine serum albumin (BSA) (Sigma) in TBS-Tween buffer $(25 \mathrm{mM}$ Tris$\mathrm{HCl}, \mathrm{pH} 7.4,3 \mathrm{mM} \mathrm{KCl}, 140 \mathrm{mM} \mathrm{NaCl}, 0.1 \%$ Tween 20) for $1 \mathrm{~h}$. After 3 washes with TBS-Tween buffer, the following primary antibodies were used according to the different assays in TBS-Tween-1\% BSA $1 \%$ buffer at the indicated dilutions and were incubated with the membrane at $4{ }^{\circ} \mathrm{C}$ overnight: rabbit anti-p125/p182 (1:4,000) (custom antibody from Eurogentec SA; discussed below), rabbit anti-AGO1 from Arabidopsis (1: 8,000) (Agrisera), or rabbit anti-AGO2 from Arabidopsis (1: 4,000) (provided by D. Baulcombe [Harvey et al. 2011]). After washing the membrane three times with TBS-Tween buffer, a secondary goat antirabbit antibody $(1: 10,000)$ (Agrisera) was added in TBS-Tween-BSA $1 \%$ at room temperature for $1 \mathrm{~h}$. After three additional washes with TBS-Tween buffer, the signals were developed by incubation at room temperature with Amersham's ECL prime Western blotting detection reagent ( $1 \mathrm{ml}$ of solution A plus $1 \mathrm{ml}$ of solution B) for $3 \mathrm{~min}$, acquiring with an Azure c600 Imager. The membrane was then stained with Amido Black to control for amount of protein loaded.

To detect ORMV p125 and p182, a primary antipeptide serum (Eurogentec SA) was raised in rabbits by immunization with a synthetic peptide (GITRADKDNVRTVDS) shared by both proteins. After purification, the antibodies were used at the suggested dilution $(1: 4,000)$.

\section{Total RNA preparation.}

For both long and small RNA blot hybridization analyses as well as Illumina deep-sequencing of sRNAs, systemic (noninoculated) leaf tissue samples from ORMV-infected and mockinoculated $A$. thaliana plants were harvested at days 5, 14, and 22 postinoculation and were frozen in liquid nitrogen. Total RNA was isolated from $0.5 \mathrm{~g}$ of ground frozen tissue from a pool of three plants, using TRI reagent (Sigma), according to the manufacturer's protocol. In the case of $N$. benthamiana, pools of leaves from two plants (infected with each ORMV construct or mock-inoculated) were harvested at day 5 and 26 postinoculation and were frozen in liquid nitrogen. Total RNA was isolated by resuspending $0.5 \mathrm{~g}$ of frozen ground tissue into $5 \mathrm{ml}$ of GHCL extraction buffer (6.5 M guanidinium hydrochloride, $100 \mathrm{mM}$ Tris-HCI, $\mathrm{pH}$ 8.0, 0.1 M sodium acetate, $\mathrm{pH}$ 5.5, $0.1 \mathrm{M}$ $\beta$-mercaptoethanol), centrifuging the resulting homogenate at $10,000 \times g$ for $10 \mathrm{~min}$ at $4^{\circ} \mathrm{C}$, and treating the supernatant according to the manufacturer's standard protocol with TRI reagent (Sigma). In all cases, RNA was quantified with a ND-1000 UV-Vis spectrophotometer (NanoDrop Technologies).

\section{RT-PCR analysis of ORMV RNA.}

Two micrograms of total RNA dissolved in DEPC-treated water were mixed with $1 \mu \mathrm{l}$ of ORMV CP_qPCR_as primer $(10 \mu \mathrm{M}), 1 \mu \mathrm{l}$ of $10 \mathrm{mM}$ dNTP mix (Sigma-Aldrich), $4 \mu \mathrm{l}$ of $5 \times$ first-strand buffer $(250 \mathrm{mM}$ Tris- $\mathrm{HCl}$ [pH 8.3], $375 \mathrm{mM} \mathrm{KCl}$, $15 \mathrm{mM} \mathrm{MgCl}_{2}$ ), and $2 \mu \mathrm{l}$ of $0.1 \mathrm{M} \mathrm{DTT}$ and were adjusted to a final volume of $18 \mu \mathrm{l}$. The mix was heated at $65^{\circ} \mathrm{C}$ for $2 \mathrm{~min}$ and was then left on ice to cool down. One microliter of RNAsin (40 units/ $\mu$ l; Promega) and $1 \mu \mathrm{l}$ of Superscript III reverse transcription (200 units per microliter; Invitrogen) were added, and the mix was left for $2 \mathrm{~min}$ at room temperature, was incubated at $50^{\circ} \mathrm{C}$ for $1 \mathrm{~h}$, and was then left at $85^{\circ} \mathrm{C}$ for $5 \mathrm{~min}$ to stop the reaction. Each reaction was diluted 1:100 with DEPC-treated water before further use.
To verify the p125 stop codon mutation and reversion, $4 \mu \mathrm{l}$ of the diluted cDNA were mixed with $2 \mu \mathrm{l}$ of oligonucleotide p180_Cla_s $(10 \mu \mathrm{M}), 2 \mu \mathrm{l}$ of oligonucleotide p180_XmaIII_as $(10 \mu \mathrm{M}), 1 \mu \mathrm{l}$ of $10 \mathrm{mM}$ dNTP mix (Sigma-Aldrich), $5 \mu \mathrm{l}$ of $10 \times$ PCR buffer (Sigma-Aldrich), and $1 \mu$ l of Vent DNA polymerase (2,000 units per milliliter; NEB), adjusting the resulting reaction to a final volume of $50 \mu \mathrm{l}$. The thermal cycling conditions were $95^{\circ} \mathrm{C}$ for $2 \mathrm{~min}, 34$ cycles of $95^{\circ} \mathrm{C}(30 \mathrm{~s}), 62^{\circ} \mathrm{C}$ $(40 \mathrm{~s})$, and $72^{\circ} \mathrm{C}(1 \mathrm{~min})$, followed by a final extension at $72^{\circ} \mathrm{C}$ (10 min). The reaction was purified with a GenElute PCR clean-up kit (Sigma), following manufacturer's instructions, and an aliquot from the resulting DNA was analyzed by agarose gel electrophoresis to check the size of the PCR products. The remaining DNA was sequenced using p180_Cla_s and p180_XmaIII_as primers.

\section{Long RNA blot hybridization analysis.}

Total RNA (20 mg) was dried in a SpeedVac and resuspended in $6 \mu \mathrm{l}$ of DEPC-treated water, was mixed with $6 \mu \mathrm{l}$ of $2 \times$ RNA gel loading dye (Thermo Fisher Scientific), was heated at $65^{\circ} \mathrm{C}$ for $3 \mathrm{~min}$, and was loaded in a $1.2 \%$ denaturing agarose gel (1.2\% agarose, $3 \%$ formaldehyde in MOPS buffer $[0.02 \mathrm{M}$ MOPS, pH 7.0, 1 mM EDTA, 5 mM NaOAc]). A RiboRuler high range RNA ladder from 200 to 6,000 bases (Thermo Fisher Scientific) was also loaded as size marker. The gel was run in a Sub-Cell GT cell (BioRad) nucleotide electrophoresis device at $100 \mathrm{~V}$, with MOPS buffer, for $4 \mathrm{~h}$, and the RNA was transferred to a Hybond $\mathrm{N}+$ membrane (Amersham) by capillary transfer for $24 \mathrm{~h}$, using $50 \mathrm{mM} \mathrm{NaH}_{2} \mathrm{PO}_{4}, 5 \mathrm{mM}$ EDTA, pH 6.5, as transfer buffer. After cross-linking twice with $1,200 \mu$ joules $\times 100 \mathrm{UV}$ light in a Stratalinker 1800 (Stratagene), the hybridization was performed as described below for sRNA blot hybridization analysis.

\section{Small RNA blot hybridization analysis.}

High-resolution sRNA blot hybridization was performed as described previously (Akbergenov et al. 2006), with some modifications. Ten micrograms or, in some cases, $30 \mu \mathrm{g}$ of total RNA were dried in a SpeedVac and were resuspended into $10 \mu \mathrm{l}$ of loading buffer (95\% formamide, $20 \mathrm{mM}$ EDTA, $\mathrm{pH} 8.0$, $0.05 \%$ bromophenol blue, $0.05 \%$ xylene cyanol), were heated at $95^{\circ} \mathrm{C}$ for $2 \mathrm{~min}$, and were loaded in a $15 \%$ polyacrylamideurea gel (19:1 acrylamide/bis-acrylamide and $8 \mathrm{M}$ urea). The gel was run using an SE 600 electrophoresis device (Hoefer) at $300 \mathrm{~V}$ for $4 \mathrm{~h}$, and the RNA was then transferred to a Hybond N+ membrane (Amersham) by electroblotting in tris-borate-EDTA (TBE) buffer at $10 \mathrm{~V}$ overnight at $4^{\circ} \mathrm{C}$. The RNA was crosslinked to the membrane twice with $1200 \mu$ joules $\times 100$ UV light in a Stratalinker 1800 (Stratagene). Blot hybridization was performed at $35^{\circ} \mathrm{C}$ overnight, in UltraHyb-oligo buffer (Ambion), using as probes one or more short DNA oligonucleotides endlabeled with $\mathrm{P}^{32}$ gamma ATP (Hartmann Analytic) by T4 polynucleotide kinase (Roche), and was purified through MicroSpin G-25 columns (Amersham), following manufacturer's recommendations. The membrane was washed three times with $2 \times$ saline-sodium citrate buffer, $\mathrm{pH} 7.0$ (SSC), $0.5 \%$ SDS for $30 \mathrm{~min}$ at $35^{\circ} \mathrm{C}$, and the data were acquired by exposure for 1 to 6 days to a phosphor screen in a GE Typhoon 8600 imager (GE Healthcare Life Sciences). For repeated hybridizations, the membrane was stripped with $0.5 \times \mathrm{SSC}, 0.5 \% \mathrm{SDS}$ for $30 \mathrm{~min}$ at $80^{\circ} \mathrm{C}$ and, then, with $0.1 \times \mathrm{SSC}, 0.5 \%$ SDS for $30 \mathrm{~min}$ at $80^{\circ} \mathrm{C}$. The DNA oligonucleotides were designed and synthesized by Eurofins S.A.

\section{$\beta$-elimination assay.}

The $\beta$-elimination experiment was performed as described previously (Akbergenov et al. 2006). Briefly, $20 \mu \mathrm{g}$ of total RNA was dissolved in $17.5 \mu \mathrm{l}$ of borax buffer, $\mathrm{pH} 8.6(4.375 \mathrm{mM}$ 
borax [Fluka], $50 \mathrm{mM}$ boric acid [Fluka]) and $2.5 \mu \mathrm{l}$ of freshly prepared $0.2 \mathrm{M}$ sodium periodate (Fluka). As an internal control of the reaction, $250 \mathrm{pg}$ of 22-nt nonmethylated RNA (5'UUCACCUUGAUGCCGUUCUUCU-3') were spiked into each sample. The reaction mixture was incubated for $10 \mathrm{~min}$ at room temperature in the dark and, after addition of $2 \mu \mathrm{l}$ of glycerol, the incubation was repeated. The mixture was dried under vacuum in a SpeedVac, was dissolved in $50 \mu \mathrm{l}$ of borax buffer, $\mathrm{pH} 9.5$ (33.75 mM borax, $50 \mathrm{mM}$ boric acid, $\mathrm{pH}$ adjusted by $\mathrm{NaOH}$ ), and was incubated for $90 \mathrm{~min}$ at $45^{\circ} \mathrm{C}$. After treatment, the RNA samples were purified with Illustra MicroSpin G-25 columns (GE Healthcare Life Sciences) and were used for sRNA blot hybridization as described above.

\section{Illumina sequencing and bioinformatics analysis of viral and plant sRNAs.}

Ten-microgram aliquots from the total RNA samples analyzed by sRNA blot hybridization were used to prepare sRNA libraries following Illumina's modified protocol for the sRNA library construction kit. Briefly, the 19- to 30-nt RNA fraction from total RNA was purified on a $15 \%$ TBE-urea acrylamide gel. A 5' adenylated single-stranded adapter was first ligated to the $3^{\prime}$ end of the RNA, using T4 RNA ligase without ATP, followed by a second single-stranded adapter ligated to the $5^{\prime}$ end of the , using T4 RNA ligase in the presence of ATP. The ligation products were purified on a $10 \%$ TBE-urea acrylamide gel before cDNA synthesis and PCR amplification, after which the resulting libraries were sequenced on an Illumina Genome Analyzer HiSeq2000 (BPO-36-44) or HiSeq2500 (BPO-137-1) following the manufacturer's protocols.

After trimming adaptor sequences, the datasets of all (redundant) reads were mapped to the reference genomes of A. thaliana Col-0 (TAIR10), N. benthamiana (Niben.genome v0.4.4; Sol Genomics Network website), or ORMV (W41, KF137561; or its mutant derivative M41), using the BurrowsWheeler Aligner v0.5.9 ( $\mathrm{Li}$ and Durbin 2009). Then, 20- to 25-nt redundant reads were taken for further bioinformatics analysis, as described previously (Rajeswaran et al. 2014). The analysis of virus-derived sRNAs and the reconstruction of a consensus master sequence and its quasispecies variants (single nucleotide polymorphisms) were done using MISIS-2 (Seguin et al. 2016). For each reference genome and sRNA size class, MISIS-2 counted total reads as well as reads in each orientation, generating single-base resolution maps that displayed, for each position starting from the $5^{\prime}$ end of the reference genome, the number of matches starting at that position in forward (first base of the read) and reverse (last base of the read) orientation per size class.

\section{Construction of expression vectors}

for ORMV p125, p125/182, and p182 proteins.

Gateway technology was used to construct vectors for expressing the ORMV proteins transiently in $N$. benthamiana or stably in transgenic $A$. thaliana. The coding sequences for $\mathrm{p} 125$ and p125/p182 were amplified from pORMV clone $\mathrm{W}$ as attBPCR products, using Vent DNA polymerase (NEB) and primers AttB1_Rep_s and 5AttB2_p125_as for p125 or AttB1_Rep_s and AttB2_p182_as for p125/p182. The latter pair of primers was also used to amplify the p182 coding sequence from the p125 stop codon mutant clone M. The resulting attB-PCR products were separately cloned into a Gateway $\mathrm{pDONR/Zeo} \mathrm{vector}$ through a BP Clonase reaction (Gateway BP Clonase Enzyme Mix; Invitrogen) to yield three different entry clones. An LR reaction (Gateway LR Clonase Enzyme mix; Invitrogen) using three different destination vectors (pEarleyGate binary constructs 100 [no tag], 201 [HA-tag], and 202 [FLAG-tag] [Earley et al. 2006]) per entry clone was then used to obtain the ORMV protein expression constructs (p125, p125-HA, p125-FG, p182, p182-HA, p182-FG, p125/182, 201-p125/182-HA, and p125/182FG). All the constructs contained the ORMV coding sequence between a CaMV $35 \mathrm{~S}$ promoter and an octopine synthase (OCS) terminator, as well as kanamycin- and phosphinotricine (or herbicide Basta)-resistance marker genes for bacterial and plant selection, respectively. The pEarleyGate 100 constructs contained the wild-type ORMV protein sequences, while the pEarleyGate 201 and 202 constructs contained an HA-tag or a FLAG-tag fused to the N-terminus of the ORMV proteins, respectively. All final pEarleyGate constructs were amplified in Escherichia coli DH5 $\alpha$ in the presence of kanamycin, were sequenced downstream of the $35 \mathrm{~S}$ promoter and upstream of the OCS terminator to verify fragment junctions, and were then mobilized to Agrobacterium tumefaciens GV3101 (rifampicin-resistant) by electroporation. The Agrobacterium colonies were selected on rifampicin and kanamycin, and the presence of each construct was confirmed by PCR, using primers CaMV35Spro_\#1 and Ormv323_as.

\section{Generation of transgenic $A$. thaliana plants.}

Transgenic plants were obtained by floral-dipping transformation (Zhang et al. 2006) with Agrobacterium strains carrying the ORMV expression constructs. Briefly, A. thaliana Col-0 plants (three plants per construct) at an early bolting stage (two months old) were cleaned from flowers and left only with closed flower buds, and were then dipped into an Agrobacterium suspension supplemented with $5 \%$ sucrose and $0.02 \%$ Silwet L-77 for transformation. After removing excess liquid, the plants were kept in the dark at $20^{\circ} \mathrm{C}$ overnight and were then placed in a light chamber at $20^{\circ} \mathrm{C}$ until siliques with mature seeds were produced. The harvested seeds were germinated and the seedlings were sprayed with a $250 \mathrm{mg}$ of Basta per liter (Bayer CropScience) solution two times per week. Basta-resistant seedlings (generation T1) were transferred to new pots and were grown until seeds were produced. These seeds were then germinated on soil and the seedlings were sprayed with the same Basta solution two times per week. Afterward, T2 Basta-resistant seedlings were transferred to new pots, and the same procedure was repeated to obtain generations T3 and T4 of Basta-resistant plants. The presence of ORMV expression constructs in the transgenic lines was confirmed by PCR genotyping, using primers CaMV35Spro_\#1 and Ormv141_as. For each transgenic line, seedlings of T2 or T3 generations were phenotyped and analyzed for ORMV protein expression and endogenous sRNAs by Western and sRNA blot hybridization, respectively, as described above.

\section{Transient expression in $N$. benthamiana.}

Transient expression experiments using the $N$. benthamiana $16 \mathrm{c}$ line were performed as described previously (Hamilton et al. 2002; Himber et al. 2003). Agrobacterium tumefaciens strains carrying a binary plasmid with a GFP coding sequence under control of the CaMV $35 \mathrm{~S}$ promoter and nopaline synthase terminator (35S:GFP), its derivatives with a potyviral pHC-Pro (35S:HcPro), or tombusviral p19 (35S:P19) coding sequence (all donated by D. Baulcombe [Hamilton et al. 2002]), and the Agrobacterium strains harboring the ORMV constructs were grown in liquid LB medium with $100 \mathrm{mg}$ of kanamycin per liter overnight at $28^{\circ} \mathrm{C}$ at $180 \mathrm{rpm}$. After centrifugation, the bacterial pellets were resuspended in $40 \mathrm{ml}$ of an infiltration buffer (10 mM 2-[N-morpholino]ethanesulphonic acid, $10 \mathrm{mM} \mathrm{MgCl}_{2}, \mathrm{pH}$ 5.6), were induced with $150 \mu \mathrm{M}$ acetosyringone for $3 \mathrm{~h}$ at room temperature, and were adjusted to an optical density at $600 \mathrm{~nm}$ of 0.5 with the infiltration buffer before agroinfiltration. The cell suspension carrying the GFP construct was mixed with an equal volume of cell suspensions carrying 
each viral construct or an empty agro suspension, infiltrating the resulting mixtures on the abaxial surface of leaves of the $N$. benthamiana $16 \mathrm{C}$ line with a $1-\mathrm{ml}$ syringe (without needle) after gently scratching it with a needle. Leaf patches infiltrated with the suspension carrying, exclusively, the GFP construct were used as a positive silencing control, whereas leaf patches infiltrated with the suspension carrying the GFP construct plus the pHC-Pro or $\mathrm{p} 19$ construct served as a strong silencing suppression control. Images of the agroinfiltrated leaves under UV light were taken at days 5, 7, and 10 days postinfiltration in order to monitor transient GFP expression in the presence or absence of the putative viral silencing suppressors. The plants were grown in soil under open greenhouse conditions at 20 to $25^{\circ} \mathrm{C}$ and were kept under the same conditions after agroinfiltration. Total RNA was extracted at 10 days post-agroinfiltration from the infiltrated leaf tissue patches ground in liquid nitrogen, using TRIzol reagent (Sigma), following the manufacturer's instructions but including an additional first step with GHCL extraction buffer, as described above, for total RNA extraction. For sRNA analysis, $10-\mu \mathrm{g}$ samples of total RNA were separated on $15 \%$ polyacrylamide gel, images of the ethidium bromidestained gels were acquired to be used as loading controls, and the RNA species were transferred to a Hybond $\mathrm{N}+$ membrane (Amersham). The blot was hybridized with ${ }^{32} \mathrm{P}$-ATP-labeled, GFP 3'UTR-specific probe mGFP5_Nosterm_as, was then stripped and hybridized with probe mGFP5_Nosterm_s, and was then stripped again and hybridized with a miR482specific probe.

\section{ACKNOWLEDGMENTS}

This work was supported by the Swiss National Science Foundation (grant 31003A_143882/1 to M. M. Pooggin) and European Cooperation in Science and Technology (COST; grant SERI number C09.0176 to L. Farinelli and M. M. Pooggin). We thank F. Ponz for the pORMV plasmid, D. Baulcombe for the AGO2 antibody, T. Blevins for critically reading the manuscript, and A. Martin for English editing.

\section{LITERATURE CITED}

Aguilar, I., Sánchez, F., Martin Martin, A., Martinez-Herrera, D., and Ponz, F. 1996. Nucleotide sequence of Chinese rape mosaic virus (oilseed rape mosaic virus), a crucifer tobamovirus infectious on Arabidopsis thaliana. Plant Mol. Biol. 30:191-197.

Akbergenov, R., Si-Ammour, A., Blevins, T., Amin, I., Kutter, C., Vanderschuren, H., Zhang, P., Gruissem, W., Meins, F., Jr., Hohn, T., and Pooggin, M. M. 2006. Molecular characterization of geminivirusderived small RNAs in different plant species. Nucleic Acids Res. 34: 462-471.

Andika, I. B., Maruyama, K., Sun, L., Kondo, H., Tamada, T., and Suzuki, N. 2015. Differential contributions of plant Dicer-like proteins to antiviral defences against potato virus $\mathrm{X}$ in leaves and roots. Plant J. 81: 781-793.

Aregger, M., Borah, B. K., Seguin, J., Rajeswaran, R., Gubaeva, E. G., Zvereva, A. S., Windels, D., Vazquez, F., Blevins, T., Farinelli, L., and Pooggin, M. M. 2012. Primary and secondary siRNAs in geminivirusinduced gene silencing. PLoS Pathog. 8:e1002941.

Bayne, E. H., Rakitina, D. V., Morozov, S. Y., and Baulcombe, D. C. 2005. Cell-to-cell movement of potato potexvirus $\mathrm{X}$ is dependent on suppression of RNA silencing. Plant J. 44:471-482.

Blevins, T., Podicheti, R., Mishra, V., Marasco, M., Wang, J., Rusch, D., Tang, H., and Pikaard, C. S. 2015. Identification of Pol IV and RDR2dependent precursors of $24 \mathrm{nt}$ siRNAs guiding de novo DNA methylation in Arabidopsis. eLife 4:e09591.

Blevins, T., Rajeswaran, R., Aregger, M., Borah, B. K., Schepetilnikov, M., Baerlocher, L., Farinelli, L., Meins, F., Jr., Hohn, T., and Pooggin, M. M. 2011. Massive production of small RNAs from a non-coding region of Cauliflower mosaic virus in plant defense and viral counter-defense. Nucleic Acids Res. 39:5003-5014.

Blevins, T., Rajeswaran, R., Shivaprasad, P. V., Beknazariants, D., Si-Ammour, A., Park, H. S., Vazquez, F., Robertson, D., Meins, F., Jr., Hohn, T., and Pooggin, M. M. 2006. Four plant Dicers mediate viral small RNA biogenesis and DNA virus induced silencing. Nucleic Acids Res. 34: 6233-6246.

Boccara, M., Sarazin, A., Thiébeauld, O., Jay, F., Voinnet, O., Navarro, L., and Colot, V. 2015. Correction: The Arabidopsis miR472-RDR6 silencing pathway modulates PAMP- and effector-triggered immunity through the post-transcriptional control of disease resistance genes. PLoS Pathog. 11:e1004814.

Bouché, N., Lauressergues, D., Gasciolli, V., and Vaucheret, H. 2006. An antagonistic function for Arabidopsis DCL2 in development and a new function for DCL4 in generating viral siRNAs. EMBO J. 25:3347-3356.

Buck, K. W. 1999. Replication of tobacco mosaic virus RNA. Philos. Trans. R. Soc. Lond. B Biol. Sci. 354:613-627.

Carbonell, A., and Carrington, J. C. 2015. Antiviral roles of plant ARGONAUTES. Curr. Opin. Plant Biol. 27:111-117.

Carbonell, A., Fahlgren, N., Garcia-Ruiz, H., Gilbert, K. B., Montgomery, T. A., Nguyen, T., Cuperus, J. T., and Carrington, J. C. 2012. Functional analysis of three Arabidopsis ARGONAUTES using slicer-defective mutants. Plant Cell 24:3613-3629.

Chapman, E. J., Prokhnevsky, A. I., Gopinath, K., Dolja, V. V., and Carrington, J. C. 2004. Viral RNA silencing suppressors inhibit the microRNA pathway at an intermediate step. Genes Dev. 18:1179-1186.

Christie, M., Brosnan, C. A., Rothnagel, J. A., and Carroll, B. J. 2011 RNA decay and RNA silencing in plants: competition or collaboration? Front. Plant Sci. 2:99.

Conti, G., Zavallo, D., Venturuzzi, A. L., Rodriguez, M. C., Crespi, M., and Asurmendi, S. 2017. TMV induces RNA decay pathways to modulate gene silencing and disease symptoms. Plant J. 89:73-84.

Csorba, T., Bovi, A., Dalmay, T., and Burgyán, J. 2007. The p122 subunit of Tobacco mosaic virus replicase is a potent silencing suppressor and compromises both small interfering RNA- and microRNA-mediated pathways. J. Virol. 81:11768-11780.

Csorba, T., Kontra, L., and Burgyán, J. 2015. viral silencing suppressors: Tools forged to fine-tune host-pathogen coexistence. Virology 479-480: 85-103.

Diaz-Pendon, J. A., Li, F., Li, W. X., and Ding, S. W. 2007. Suppression of antiviral silencing by cucumber mosaic virus $2 \mathrm{~b}$ protein in Arabidopsis is associated with drastically reduced accumulation of three classes of viral small interfering RNAs. Plant Cell 19:2053-2063.

Ding, X. S., Liu, J., Cheng, N. H., Folimonov, A., Hou, Y. M., Bao, Y., Katagi, C., Carter, S. A., and Nelson, R. S. 2004. The Tobacco mosaic virus $126-\mathrm{kDa}$ protein associated with virus replication and movement suppresses RNA silencing. Mol. Plant-Microbe Interact 17:583-592.

Donaire, L., Barajas, D., Martínez-García, B., Martínez-Priego, L., Pagán, I., and Llave, C. 2008. Structural and genetic requirements for the biogenesis of tobacco rattle virus-derived small interfering RNAs. J. Virol. 82:5167-5177.

Earley, K. W., Haag, J. R., Pontes, O., Opper, K., Juehne, T., Song, K., and Pikaard, C. S. 2006. Gateway-compatible vectors for plant functional genomics and proteomics. Plant J. 45:616-629.

Elvira-Matelot, E., Hachet, M., Shamandi, N., Comella, P., Sáez-Vásquez, J., Zytnicki, M., and Vaucheret, H. 2016. Arabidopsis RNASE THREE LIKE2 modulates the expression of protein-coding genes via 24nucleotide small interfering RNA-directed DNA methylation. Plant Cell 28:406-425.

Flynt, A., Liu, N., Martin, R., and Lai, E. C. 2009. Dicing of viral replication intermediates during silencing of latent Drosophila viruses. Proc. Natl. Acad. Sci. U.S.A. 106:5270-5275.

Fusaro, A. F., Matthew, L., Smith, N. A., Curtin, S. J., Dedic-Hagan, J., Ellacott, G. A., Watson, J. M., Wang, M. B., Brosnan, C., Carroll, B. J., and Waterhouse, P. M. 2006. RNA interference-inducing hairpin RNAs in plants act through the viral defence pathway. EMBO Rep. 7:11681175

Garcia-Ruiz, H., Carbonell, A., Hoyer, J. S., Fahlgren, N., Gilbert, K. B., Takeda, A., Giampetruzzi, A., Garcia Ruiz, M. T., McGinn, M. G., Lowery, N., Martinez Baladejo, M. T., and Carrington, J. C. 2015. Roles and programming of Arabidopsis ARGONAUTE proteins during Turnip mosaic virus infection. PLoS Pathog. 11:e1004755.

Garcia-Ruiz, H., Takeda, A., Chapman, E. J., Sullivan, C. M., Fahlgren, N., Brempelis, K. J., and Carrington, J. C. 2010. Arabidopsis RNAdependent RNA polymerases and dicer-like proteins in antiviral defense and small interfering RNA biogenesis during Turnip mosaic virus infection. Plant Cell 22:481-496.

Ghildiyal, M., and Zamore, P. D. 2009. Small silencing RNAs: an expanding universe. Nat. Rev. Genet. 10:94-108.

Ghoshal, B., and Sanfaçon, H. 2014. Temperature-dependent symptom recovery in Nicotiana benthamiana plants infected with tomato ringspot virus is associated with reduced translation of viral RNA2 and requires ARGONAUTE 1. Virology 456-457:188-197. 
Hagiwara, Y., Komoda, K., Yamanaka, T., Tamai, A., Meshi, T., Funada, R., Tsuchiya, T., Naito, S., and Ishikawa, M. 2003. Subcellular localization of host and viral proteins associated with tobamovirus RNA replication. EMBO J. 22:344-353.

Hagiwara-Komoda, Y., Hirai, K., Mochizuki, A., Nishiguchi, M., Meshi, T., and Ishikawa, M. 2008. Overexpression of a host factor TOM1 inhibits tomato mosaic virus propagation and suppression of RNA silencing. Virology 376:132-139.

Hamilton, A., Voinnet, O., Chappell, L., and Baulcombe, D. 2002. Two classes of short interfering RNA in RNA silencing. EMBO J. 21: 4671-4679.

Harris, C. J., Molnar, A., Müller, S. Y., and Baulcombe, D. C. 2015. FDFPAGE: a powerful technique revealing previously undetected small RNAs sequestered by complementary transcripts. Nucleic Acids Res. 43: 7590-7599.

Harvey, J. J., Lewsey, M. G., Patel, K., Westwood, J., Heimstädt, S., Carr, J. P., and Baulcombe, D. C. 2011. An antiviral defense role of AGO2 in plants. PLoS One 6:e14639.

Havecker, E. R., Wallbridge, L. M., Hardcastle, T. J., Bush, M. S., Kelly, K. A., Dunn, R. M., Schwach, F., Doonan, J. H., and Baulcombe, D. C. 2010. The Arabidopsis RNA-directed DNA methylation argonautes functionally diverge based on their expression and interaction with target loci. Plant Cell 22:321-334.

Himber, C., Dunoyer, P., Moissiard, G., Ritzenthaler, C., and Voinnet, O. 2003. Transitivity-dependent and -independent cell-to-cell movement of RNA silencing. EMBO J. 22:4523-4533.

Howell, M. D., Fahlgren, N., Chapman, E. J., Cumbie, J. S., Sullivan, C. M., Givan, S. A., Kasschau, K. D., and Carrington, J. C. 2007. Genome-wide analysis of the RNA-DEPENDENT RNA POLYMERASE6/DICERLIKE4 pathway in Arabidopsis reveals dependency on miRNA- and tasiRNA-directed targeting. Plant Cell 19:926-942.

Hu, Q., Hollunder, J., Niehl, A., Kørner, C. J., Gereige, D., Windels, D., Arnold, A., Kuiper, M., Vazquez, F., Pooggin, M., and Heinlein, M. 2011. Specific impact of tobamovirus infection on the Arabidopsis small RNA profile. PLoS One 6:e19549.

Ishikawa, M., Meshi, T., Motoyoshi, F., Takamatsu, N., and Okada, Y. 1986. In vitro mutagenesis of the putative replicase genes of tobacco mosaic virus. Nucleic Acids Res. 14:8291-8305.

Ishikawa, M., and Okada, Y. 2004. Replication of tobamovirus RNA. Proc. Jpn. Acad. Ser. B 80:215-224.

Knapp, E., Dawson, W. O., and Lewandowski, D. J. 2001. Conundrum of the lack of defective RNAs (dRNAs) associated with tobamovirus Infections: dRNAs that can move are not replicated by the wild-type virus; dRNAs that are replicated by the wild-type virus do not move. J. Virol. 75:5518-5525.

Komoda, K., Mawatari, N., Hagiwara-Komoda, Y., Naito, S., and Ishikawa, M. 2007. Identification of a ribonucleoprotein intermediate of tomato mosaic virus RNA replication complex formation. J. Virol. 81: 2584-2591.

Kørner, C. J., Klauser, D., Niehl, A., Domínguez-Ferreras, A., Chinchilla, D., Boller, T., Heinlein, M., and Hann, D. R. 2013. The immunity regulator BAK1 contributes to resistance against diverse RNA viruses. Mol. Plant-Microbe Interact 26:1271-1280.

Kubota, K., Tsuda, S., Tamai, A., and Meshi, T. 2003. Tomato mosaic virus replication protein suppresses virus-targeted posttranscriptional gene silencing. J. Virol. 77:11016-11026.

Kurihara, Y., Inaba, N., Kutsuna, N., Takeda, A., Tagami, Y., and Watanabe, Y. 2007. Binding of tobamovirus replication protein with small RNA duplexes. J. Gen. Virol. 88:2347-2352.

Lakatos, L., Csorba, T., Pantaleo, V., Chapman, E. J., Carrington, J. C. Liu, Y. P., Dolja, V. V., Calvino, L. F., López-Moya, J. J., and Burgyán, J. 2006. Small RNA binding is a common strategy to suppress RNA silencing by several viral suppressors. EMBO J. 25: 2768-2780

Lee, W. S., Fu, S. F., Li, Z., Murphy, A. M., Dobson, E. A., Garland, L., Chaluvadi, S. R., Lewsey, M. G., Nelson, R. S., and Carr, J. P. 2016. Salicylic acid treatment and expression of an RNA-dependent RNA polymerase 1 transgene inhibit lethal symptoms and meristem invasion during tobacco mosaic virus infection in Nicotiana benthamiana. BMC Plant Biol. 16:15.

Lewandowski, D. J., and Dawson, W. O. 2000. Functions of the 126- and $183-\mathrm{kDa}$ proteins of tobacco mosaic virus. Virology 271:90-98.

Li, H., and Durbin, R. 2009. Fast and accurate short read alignment with Burrows-Wheeler transform. Bioinformatics 25:1754-1760.

Lózsa, R., Csorba, T., Lakatos, L., and Burgyán, J. 2008. Inhibition of 3' modification of small RNAs in virus-infected plants require spatial and temporal co-expression of small RNAs and viral silencing-suppressor proteins. Nucleic Acids Res. 36:4099-4107.
Ma, X., Nicole, M. C., Meteignier, L. V., Hong, N., Wang, G., and Moffett, P. 2015. Different roles for RNA silencing and RNA processing components in virus recovery and virus-induced gene silencing in plants. J. Exp. Bot. 66:919-932.

Mansilla, C., Sánchez, F., Padgett, H. S., Pogue, G. P., and Ponz, F. 2009. Chimeras between oilseed rape mosaic virus and tobacco mosaic virus highlight the relevant role of the tobamoviral $\mathrm{RdRp}$ as pathogenicity determinant in several hosts. Mol. Plant Pathol. 10:59-68.

Mérai, Z., Kerényi, Z., Kertész, S., Magna, M., Lakatos, L., and Silhavy, D. 2006. Double-stranded RNA binding may be a general plant RNA viral strategy to suppress RNA silencing. J. Virol. 80: 5747-5756.

Mi, S., Cai, T., Hu, Y., Chen, Y., Hodges, E., Ni, F., Wu, L., Li, S., Zhou, H., Long, C., Chen, S., Hannon, G. J., and Qi, Y. 2008. Sorting of small RNAs into Arabidopsis argonaute complexes is directed by the $5^{\prime}$ terminal nucleotide. Cell 133:116-127.

Mlotshwa, S., Pruss, G. J., Peragine, A., Endres, M. W., Li, J., Chen, X., Poethig, R. S., Bowman, L. H., and Vance, V. 2008. DICER-LIKE2 plays a primary role in transitive silencing of transgenes in Arabidopsis. PLoS One 3:e1755.

Molnár, A., Csorba, T., Lakatos, L., Várallyay, E., Lacomme, C., and Burgyán, J. 2005. Plant virus-derived small interfering RNAs originate predominantly from highly structured single-stranded viral RNAs. J. Virol. 79:7812-7818.

Nicaise, V., and Candresse, T. 2017. Plum pox virus capsid protein suppresses plant pathogen-associated molecular pattern (PAMP)-triggered immunity. Mol. Plant Pathol. 18:878-886.

Niehl, A., Wyrsch, I., Boller, T., and Heinlein, M. 2016. Double-stranded RNAs induce a pattern-triggered immune signaling pathway in plants. New Phytol. 211:1008-1019.

Nishikiori, M., Meshi, T., and Ishikawa, M. 2012. Guanylylation-competent replication proteins of Tomato mosaic virus are disulfide-linked. Virology 434:118-128.

Odokonyero, D., Mendoza, M. R., Alvarado, V. Y., Zhang, J., Wang, X., and Scholthof, H. B. 2015. Transgenic down-regulation of ARGONAUTE2 expression in Nicotiana benthamiana interferes with several layers of antiviral defenses. Virology 486:209-218.

Osman, T. A., and Buck, K. W. 1996. Complete replication in vitro of tobacco mosaic virus RNA by a template-dependent, membrane-bound RNA polymerase. J. Virol. 70:6227-6234.

Palukaitis, P., García-Arenal, F., Sulzinski, M. A., and Zaitlin, M. 1983. Replication of tobacco mosaic virus. VII. Further characterization of single- and double-stranded virus-related RNAs from TMV-infected plants. Virology 131:533-545.

Parent, J. S., Bouteiller, N., Elmayan, T., and Vaucheret, H. 2015. Respective contributions of Arabidopsis DCL2 and DCL4 to RNA silencing. Plant J. 81:223-232.

Qi, X., Bao, F. S., and Xie, Z. 2009. Small RNA deep sequencing reveals role for Arabidopsis thaliana RNA-dependent RNA polymerases in viral siRNA biogenesis. PLoS One 4:e4971.

Qu, F., Ye, X., Hou, G., Sato, S., Clemente, T. E., and Morris, T. J. 2005 RDR6 has a broad-spectrum but temperature-dependent antiviral defense role in Nicotiana benthamiana. J. Virol. 79:15209-15217.

Rajeswaran, R., Aregger, M., Zvereva, A. S., Borah, B. K., Gubaeva, E. G. and Pooggin, M. M. 2012. Sequencing of RDR6-dependent doublestranded RNAs reveals novel features of plant siRNA biogenesis. Nucleic Acids Res. 40:6241-6254.

Rajeswaran, R., Golyaev, V., Seguin, J., Zvereva, A. S., Farinelli, L., and Pooggin, M. M. 2014. Interactions of rice tungro bacilliform pararetrovirus and its protein $\mathrm{P} 4$ with plant RNA-silencing machinery. Mol. Plant-Microbe Interact 27:1370-1378.

Rajeswaran, R., and Pooggin, M. M. 2012. RDR6-mediated synthesis of complementary RNA is terminated by miRNA stably bound to template RNA. Nucleic Acids Res. 40:594-599.

Scholthof, H. B., Alvarado, V. Y., Vega-Arreguin, J. C., Ciomperlik, J., Odokonyero, D., Brosseau, C., Jaubert, M., Zamora, A., and Moffett, P. 2011. Identification of an ARGONAUTE for antiviral RNA silencing in Nicotiana benthamiana. Plant Physiol. 156:1548-1555.

Schwach, F., Vaistij, F. E., Jones, L., and Baulcombe, D. C. 2005. An RNAdependent RNA polymerase prevents meristem invasion by potato virus $\mathrm{X}$ and is required for the activity but not the production of a systemic silencing signal. Plant Physiol. 138:1842-1852.

Seguin, J., Otten, P., Baerlocher, L., Farinelli, L., and Pooggin, M. M. 2016. MISIS-2: A bioinformatics tool for in-depth analysis of small RNA and representation of consensus master genome in viral quasispecies. J. Virol. Methods 233:37-40.

Seguin, J., Rajeswaran, R., Malpica-López, N., Martin, R. R., Kasschau, K., Dolja, V. V., Otten, P., Farinelli, L., and Pooggin, M. M. 2014. De novo 
reconstruction of consensus master genomes of plant RNA and DNA viruses from siRNAs. PLoS One 9:e88513.

Shamandi, N., Zytnicki, M., Charbonnel, C., Elvira-Matelot, E., Bochnakian, A., Comella, P., Mallory, A. C., Lepère, G., Sáez-Vásquez, J., and Vaucheret, H. 2015. Plants encode a general sirna suppressor that is induced and suppressed by viruses. PLoS Biol. 13:e1002326.

Shivaprasad, P. V., Rajeswaran, R., Blevins, T., Schoelz, J., Meins, F., Jr., Hohn, T., and Pooggin, M. M. 2008. The CaMV transactivator/viroplasmin interferes with RDR6-dependent trans-acting and secondary siRNA pathways in Arabidopsis. Nucleic Acids Res. 36:5896-5909.

Smith, N. A., Eamens, A. L., and Wang, M. B. 2010. The presence of highmolecular-weight viral RNAs interferes with the detection of viral small RNAs. RNA 16:1062-1067.

Vaistij, F. E., and Jones, L. 2009. Compromised virus-induced gene silencing in RDR6-deficient plants. Plant Physiol. 149:1399-1407.

Várallyay, E., and Havelda, Z. 2013. Unrelated viral suppressors of RNA silencing mediate the control of ARGONAUTE1 level. Mol. Plant Pathol. 14:567-575

Várallyay, E., Válóczi, A., Agyi, A., Burgyán, J., and Havelda, Z. 2010. Plant virus-mediated induction of miR168 is associated with repression of ARGONAUTE1 accumulation. EMBO J. 29:3507-3519.

Vaucheret, H., Mallory, A. C., and Bartel, D. P. 2006. AGO1 homeostasis entails coexpression of MIR168 and AGO1 and preferential stabilization of miR168 by AGO1. Mol. Cell 22:129-136.

Vogler, H., Akbergenov, R., Shivaprasad, P. V., Dang, V., Fasler, M., Kwon, M. O., Zhanybekova, S., Hohn, T., and Heinlein, M. 2007. Modification of small RNAs associated with suppression of RNA silencing by tobamovirus replicase protein. J. Virol. 81:10379-10388.

Wang, X. B., Jovel, J., Udomporn, P., Wang, Y., Wu, Q., Li, W. X., Gasciolli, V., Vaucheret, H., and Ding, S. W. 2011. The 21-nucleotide, but not 22-nucleotide, viral secondary small interfering RNAs direct potent antiviral defense by two cooperative argonautes in Arabidopsis thaliana. Plant Cell 23:1625-1638.

Wang, X. B., Wu, Q., Ito, T., Cillo, F., Li, W. X., Chen, X., Yu, J. L., and Ding, S. W. 2010. RNAi-mediated viral immunity requires amplification of virus-derived siRNAs in Arabidopsis thaliana. Proc. Natl. Acad. Sci. U.S.A. 107:484-489.

Wassenegger, M., and Krczal, G. 2006. Nomenclature and functions of RNA-directed RNA polymerases. Trends Plant Sci. 11:142-151.

Watanabe, T., Honda, A., Iwata, A., Ueda, S., Hibi, T., and Ishihama, A. 1999. Isolation from tobacco mosaic virus-infected tobacco of a solubilized template-specific RNA-dependent RNA polymerase containing a $126 \mathrm{~K} / 183 \mathrm{~K}$ protein heterodimer. J. Virol. 73:2633-2640.
Xie, Z., Johansen, L. K., Gustafson, A. M., Kasschau, K. D., Lellis, A. D. Zilberman, D., Jacobsen, S. E., and Carrington, J. C. 2004. Genetic and functional diversification of small RNA pathways in plants. PLoS Biol. 2:e104.

Yang, S. J., Carter, S. A., Cole, A. B., Cheng, N. H., and Nelson, R. S. 2004. A natural variant of a host RNA-dependent RNA polymerase is associated with increased susceptibility to viruses by Nicotiana benthamiana. Proc. Natl. Acad. Sci. U.S.A. 101:6297-6302.

Yang, Z., Ebright, Y. W., Yu, B., and Chen, X. 2006. HEN1 recognizes 2124 nt small RNA duplexes and deposits a methyl group onto the $2^{\prime} \mathrm{OH}$ of the 3' terminal nucleotide. Nucleic Acids Res. 34:667-675.

Yu, B., Yang, Z., Li, J., Minakhina, S., Yang, M., Padgett, R. W., Steward, R., and Chen, X. 2005. Methylation as a crucial step in plant microRNA biogenesis. Science 307:932-935.

Yu, D., Fan, B., MacFarlane, S. A., and Chen, Z. 2003. Analysis of the involvement of an inducible Arabidopsis RNA-dependent RNA polymerase in antiviral defense. Mol. Plant-Microbe Interact 16:206-216.

Zavallo, D., Debat, H. J., Conti, G., Manacorda, C. A., Rodriguez, M. C. and Asurmendi, S. 2015. Differential mRNA accumulation upon early Arabidopsis thaliana infection with ORMV and TMV-Cg Is associated with distinct endogenous small RNAs level. PLoS One 10:e134719.

Zhai, J., Bischof, S., Wang, H., Feng, S., Lee, T. F., Teng, C., Chen, X., Park, S. Y., Liu, L., Gallego-Bartolome, J., Liu, W., Henderson, I. R., Meyers, B. C., Ausin, I., and Jacobsen, S. E. 2015. A one precursor one siRNA model for Pol IV-dependent siRNA biogenesis. Cell 163:445455.

Zhang, X., Henriques, R., Lin, S. S., Niu, Q. W., and Chua, N. H. 2006. Agrobacterium-mediated transformation of Arabidopsis thaliana using the floral dip method. Nat. Protoc. 1:641-646.

Zvereva, A. S., Golyaev, V., Turco, S., Gubaeva, E. G., Rajeswaran, R., Schepetilnikov, M. V., Srour, O., Ryabova, L. A., Boller, T., and Pooggin, M. M. 2016. Viral protein suppresses oxidative burst and salicylic aciddependent autophagy and facilitates bacterial growth on virus-infected plants. New Phytol. 211:1020-1034.

Zvereva, A. S., and Pooggin, M. M. 2012. Silencing and innate immunity in plant defense against viral and non-viral pathogens. Viruses 4:2578-2597.

\section{AUTHOR-RECOMMENDED INTERNET RESOURCES}

MISIS-2 software: www.fasteris.com/apps

Sol Genomics Network Nicotiana benthamiana draft genome sequence: https://solgenomics.net/organism/Nicotiana_benthamiana/genome 